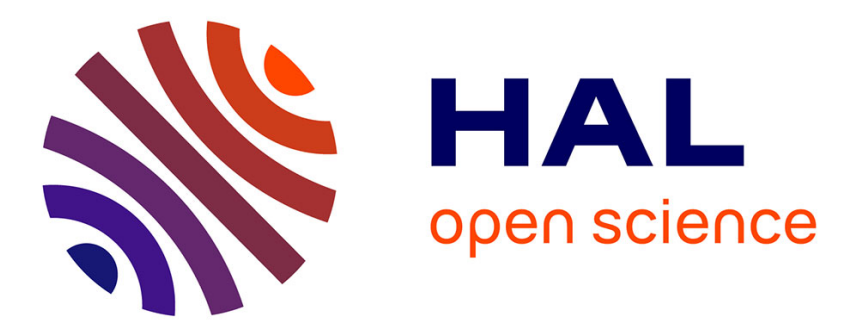

\title{
Dans l'atelier des faussaires. Luc de Túy, Rodrigue de Tolède, Alphonse X, Sanche IV : trois exemples de manipulations historiques (León-Castille, xiiie siècle)
}

Georges Martin

\section{- To cite this version:}

Georges Martin. Dans l'atelier des faussaires. Luc de Túy, Rodrigue de Tolède, Alphonse X, Sanche IV : trois exemples de manipulations historiques (León-Castille, xiiie siècle). Cahiers de Linguistique et de Civilisation Hispaniques Médiévales, 2001, 24, pp.279-309. halshs-00009825

\section{HAL Id: halshs-00009825 \\ https://shs.hal.science/halshs-00009825}

Submitted on 30 Mar 2006

HAL is a multi-disciplinary open access archive for the deposit and dissemination of scientific research documents, whether they are published or not. The documents may come from teaching and research institutions in France or abroad, or from public or private research centers.
L'archive ouverte pluridisciplinaire HAL, est destinée au dépôt et à la diffusion de documents scientifiques de niveau recherche, publiés ou non, émanant des établissements d'enseignement et de recherche français ou étrangers, des laboratoires publics ou privés. 


\section{Dans l'atelier des faussaires. Luc de Túy, Rodrigue de Tolède, Alphonse X, Sanche IV : trois exemples de manipulations historiques (León-C astille, $\mathrm{x}$ III e siècle)}

Q uelle joie de participer à la première rencontre qui se soit jamais tenue sur l'œuvre de Luc de Túy! II n'est pas si loin le temps où, écrivant $L$ es J uges de C astille et même quel ques articles postérieurs, je formais chaque fois le vœu qu'un chercheur s'intéressât à cet homme qui, dans la première moitié du XIIIe siècle, réinventa - avec quel astucieux aplomb ! I'histoire d'E spagne et l'art de la rapporter. L orsque L uc de T úy se met à l'ouvrage, peu avant 1236, I'historiographie royale est presque morte en León comme en Castille. Longtemps après le travail des fondateurs asturiens, dont la Chronique d'Alphonse III avait, au tournant des IX ${ }^{\mathrm{e}}$ et $X{ }^{e}$ siècles, couronné l'effort, la suite léonaise du $X I^{e}$ siècle et de la première moitié du X II - Chronique de Sampiro, Corpus pélagien, H istoria silensis - avait amené, aux environs de 1160, dans la R ioja castillane, une belle et claire synthèse: la Chronica najerensis. Peu avant, le royaume léonais avait encore produit la Chronica Adefonsi imperatoris, première chronique post-wisigothique entièrement consacrée à un règne, qui prolongeait en fait, par un récit contemporain des faits d'Alphonse VII, le savoir historiographique traditionnel. Ensuite, plus rien ou presque pour près d'un siècle. Seul le Liber regum, mais en N avarre et avant 1194, témoigne de la persistance d'une activité historiographique. Encore s'agit-il, pour l'essentiel, d'un résumé de chroniques, habilement agencé, certes, mais étroitement tributaire de l'art ancien de la généalogie royale. La composition du Liber, dont le titre usuel masque l'avènement majeur qu'il constitue, celui d'une historiographie en langue vernaculaire, traduisait pourtant le souci de diffuser plus largement 
I'histoire des rois. M ais en León et en Castille - si l'on excepte, pour cette dernière, I'activité des annalistes - rien jusqu'à Luc, rien entre 1160 et 1236, date d'achèvement du Chronicon mundi. Un long silence historiographique couvre presque l'entier du règne, sous tous rapports si important, d'Alphonse VIII (1158-1217) ${ }^{1}$ et les vingt premières années de celui de Ferdinand III. Vers 1220 encore, I'archevêque de Tolède Rodrigue Jimenez de Rada, appelé, pourtant, à être le plus grand historien du X $\mathrm{II}^{\mathrm{e}}$ siècle espagnol, se contente de faire traduire dans l'atelier de sa cathédrale le L iber regum du navarrais au castillan.

$O \mathrm{r}$, voici que tout change en 1236 . L'année où le Léonais L uc de T úy met fin à son Chronicon voit aussi l'achèvement de l'anonyme $C$ hronique latine des rois de Castille. D ès 1243, en C astille également, R odrigue Jimenez de R ada conclut le $\mathrm{D}$ e rebus $\mathrm{H}$ ispaniae, qu'il parachèvera en 1246. Peu après 1270, l'atelier historiographique d'Alphonse $X$ le Sage est près d'achever I'E stoire d'E spagne et a entrepris la composition d'une $G$ rande et générale estoire, le reste du règne étant occupé par la continuation ou la refonte de ces œuvres ambitieuses. Ainsi, après un silence de près d'un siècle, cinq chroniques royales dont une universelle en guère plus de trente ans!

Cet essor n'est pas sans lien avec un contexte politique: I'union - non dépourvue de rivalité et surtout de discordances de toutes sortes - du León avec la Castille à partir de 1230, l'expansion fulgurante de ces deux royaumes aux dépens des almohades puis des taïfas dans le deuxième quart du $X I I^{e}$ siècle, le renforcement de la royauté, son application à consolider les bases d'un État. $M$ ais ce lien s'établit par I'intermédiaire des hommes et c'est, en l'occurrence, bien souvent la relation humaine - intellectuelle, «naturelle», politique - entre personnalités qui a d'abord décidé de la prolifération des textes, de leur sens et de leurs contrastes. Luc de Túy, Rodrigue de Tolède et Alphonse $X$ le Sage - auxquels j'ai ajouté, parce qu'il suscite, non loin de ce premier trio, autour de 1289, une révision fort intéressante de l'E stoire d'E spagne, Sanche IV (et sa femme M arie de M olina, dont l'influence politique, non seulement au long du règne de son époux mais encore sous ceux de son fils Ferdinand IV et de son petit-fils Alphonse XI, fut si déterminante que l'on parle aujourd'hui de « molinisme » pour désigner une idéologie politique qui baigne près d'un demi-siècle de l'histoire de la C astille), voilà - si on laisse de côté la Chronique latine, dont le castillanocentrisme est souverainement intéressant mais qui fut sans influence sur

1. Sur l'activité culturelle à la cour d'Alphonse VIII, voir notamment Adeline RU CQU OI, "La royauté sous Alphonse VIII de Castille », Cahiers de linguistique hispanique médiévale, 23, 2000 , p. 215-241. 
notre tétralogue et qui ne traite pas des thèmes sur lesquels nous nous pencherons - , voilà les auteurs et les patrons dont les relations permettent de comprendre les enjeux et de saisir le sens d'œuvres historiquement indissociables et qui, en chaîne, se sont motivées l'une l'autre. Les illustrations de ce jeu de reprises et de contrastes, ainsi que des conflits d'intérêts et des combats doctrinaux qu'ils traduisent, seraient innombrables. Nous en examinerons trois qui ressortissent à différents domaines de préoccupation.

\section{LE SIÈGE DE LA PRIMATIE D'E SPAGNE²}

Plaçons-nous donc en 1236. Le roi Ferdinand III, qui règne en Castille depuis 1217 et en León depuis 1230, vient de prendre Cordoue, I'ancienne capitale du califat d'Espagne. Cette conquête, si symbolique, vient couronner un mouvement d'expansion sans précédent. Depuis 1224, où fut prise Q uesada, il ne s'est guère passé d'année qui n'ait vu tomber aux mains des chrétiens une ville importante: $M$ artos et $A$ ndújar en 1225, Priego et Loja en 1226, Capilla, Baeza et Cáceres en 1227, Elvas et M ontánchez en 1229, M érida et Badajoz en 1230, Ú beda en 1232, Trujillo et M ontiel en 1233, M edellín, Alange, M agacela et Santa Cruz en 1234-1235. D ès 1240 commence l'encerclement stratégique de Séville qui s'achèvera par la prise de la ville en 1248. D ans cette avancée générale, la Castille s'est taillée la meilleure part: en terres, en hommes et en richesses. Elle fait figure en Espagne de royaume hégémonique, chargé d'avenir, tandis que le L eón, espace lointainement fondateur dont elle avait été un comté, commence de représenter un ordre ancien. L'histoire politique immédiate - qui rappelait celle, encore mal perçue par les élites léonaises, de l'accession de Ferdinand Ier de C astille au trône léonais en 1037 - évoquait une sorte d'annexion du León par la Castille. $C^{\prime}$ 'est contre le testament d'Alphonse IX qui léguait le royaume à ses deux filles, contre un grand secteur de la noblesse léonaise et - même si plusieurs prélats avaient fortement soutenu le parti castillan - contre un sentiment profond de secteurs traditionnels de l'Église de León, que le roi de Castille dut, à l'occasion par la force, imposer son pouvoir ${ }^{3}$. La mère de Ferdinand III, Bérengère, qui avait contribué si directement au

2. Peter LINEH AN, H istory and thehistorians of medieval Spain, 0 xford: Clarendon Press, 1993, p. 356-405.

3. Sur ce contexte politique, voir G eorges MARTIN, Les ] uges de Castille M entalités et discours historique dans I'E spagne médiévale, Paris: K lincksieck, 1992, p. 201-211 et 251-255. Sur le règne de Ferdinand III, les études nombreuses d'Ana RO D R I GUEZ LÓ PEZ et notamment: «La política eclesiástica de la monarquía castellano-leonesa durante el reinado de Fernando III (1217-1252) », H ispania, 168, 1988, p. 7-48; La consolidación territorial de la monarquía feudal 
couronnement de son fils dans les deux royaumes, s'installa du coup à L eón, d'où elle contrôlait de fait le royaume tandis que son fils guerroyait sur les confins andalous. Elle adossa sa demeure aux murs de SaintI sidore qui abritaient une communauté de chanoines augustins. C elle-ci n'était pas sans prestige intellectuel : elle veillait sur les restes d'I sidore de Séville et avait été dirigée naguère par le célèbre $M$ artin dont le diacre actuel, Luc, préservait la mémoire et poursuivait l'œuvre hagiographique et théologique 4 . C'est à ce dernier que Bérengère confia de « copier » et de « parachever » les « livres des chroniques de saint I sidore et d'autres experts de l'histoire des rois d'Espagne ». Luc « [se soumit] fidèlement aux souhaits de la reine », non sans la détermination intime son œuvre, partout, en témoigne - d'ajuster la tradition historiographique à ses propres convictions ${ }^{5}$.

Les convictions de notre chanoine sont d'abord pro-léonaises et anticastillanes. Les exemples, qui abondent, d'une valorisation tendancieuse du royaume de León au détriment de la Castille sont désormais bien connus ${ }^{6}$. N ous reviendrons seulement sur l'un d'entre eux, important, complexe et illustratif d'un aspect proprement ecclésial non seule-

castellana. Expansión y fronteras duranteel reinado de Fernando III, M adrid: CSIC (Biblioteca de historia, 27), 1994 et « "R ico fincas de tierra et de muchos buenos vasallos, mas que rey que en la cristiandat ssea". La herencia regia de Alfonso X », Cahiers de linguistique hispanique médiévale, 23, 2000, p. 243-261.

4. Sur cette activité, voir dans ce même volume l'étude de Patrick HENR IET.

5. Luc de TÚY, Chronicon mundi, in: Andreas SC H OTT (éd.), H ispaniaeillustratae... , 4 t. en 3 vol., Francfort, 1603-1608, 4, p. 1-119: «Astrictis praeceptis gloriosissimae ac prudentissimae $\mathrm{H}$ ispaniarum R egine dominae Berengariae, quae ut chronicorum libros à beato I sidoro $\&$ à quibusdam aliis peritis de historia R egum $\mathrm{H}$ ispanorum \& quorundam aliorum editos sibi scriberem imperavit... » (p. 1) et « N os vero ad libros chronicorum à doctore $\mathrm{H}$ ispaniarum I sidoro editos manum mittimus, secundum etiam quosdam alios $\mathrm{H}$ ispanorum $\mathrm{R}$ egum $\&$ aliorum quorundam seriem prosequendo praeceptis gloriosissimae $H$ ispaniarum R eginae dominae Berengariae omni desiderio desiderantes fideliter satisfacere. I psa enim, cujus catholicis praeceptis non licet nec libet resistere, mihi L ucae indigno diacono, ut hoc perficerem, imperavit » (p. 3). Désormais, Chronicon.

6. Respectant la chronologie, on pourra se reporter aux travaux de Georges M ARTIN : Les J uges de Castille... , p. 197-249 et «L'escarboucle de Saint-D enis, le roi de France et l'empereur des Espagnes », in: Françoise AUTR AND, Claude GAUVARD et Jean-M arie M OEG LIN (éd.), Saint-D enis et la royauté. É tudes offertes à Bernard Guenée (Paris: Publications de la Sorbonne, 1999, p. 439- 462; de Peter LINEH AN : H istory and the historians... (réf. note 1), « From chronicle to history: concerning the E storia de E spaña an its principal sources » ; in : A lan DEY ER M OND (éd.), H istorical literature in medieval I beria, L ondres (Q ueen M ary and Westfield College): Papers of the M edieval Hispanic Research Seminar, 1996, p. 7-33 et «Reflexiones sobre historiografía e historia en el siglo alfonsino », C ahiers de linguistique hispanique médiévale, 23, 2000, p. 101-111; de Patrick H EN R IET : «H agiographie et historiographie en péninsule ibérique (X|e-X III $\left.\right|^{e}$ siècles). Q uelques remarques », Cahiers de linguistique hispanique médiévale, 23,2000 , p. $53-85$, et surtout "X énophobie et intégration isidoriennes à León au $X I I I$ e siècle. Le discours de Lucas de T úy sur les étrangers », in: L'étranger au M oyen Âge Actes du XXX X congrès de la SH H M ESP (Göttingen, 1999), Paris: Publications de la Sorbonne, 2000, p. 37-58. 
ment des inquiétudes de Luc mais encore de celles des historiens qui sauront le lire et entendront, à leur tour, tirer la couverture à soi.

L'avancée des armées chrétiennes vers Séville, vers la cité dont le saint patron de l'établissement de L uc avait été l'archevêque, intéressait vivement un anti-castillan qu'agaçait la préséance primatiale de Tolède. Ne pouvait-on, remontant aux origines de l'héritage, rêver qu'une nouvelle É glise d'E spagne, isidorienne et centrée sur une primatie sévillane, achèvement du néo-wisigothisme léonais, supplantât le pouvoir tolé dan? Luc $^{7}$ se porte perfidement en territoire ennemi et invente une source: une chronique qu'aurait écrite Ildephonse, archevêque de Tolède et primat des Espagnes ${ }^{8}$. II y trouve l'information qu'I sidore après son frère aîné Léandre, lui-même archevêque de Séville ${ }^{9}$ - avait été primat de l'É glise d'Espagne ${ }^{10}$ et légat pontifical, que le roi $\mathrm{C}$ hindasvinthe (642-653) avait obtenu du pape un « privilège » autorisant les évêques espagnols à décider de ce que la primatie eût son siège soit à Séville soit à Tolède ${ }^{11}$, que l'hérésie et finalement l'apostasie du successeur d'Isidore, l'abominable et parfaitement imaginaire Théodiscle, amena le roi Chindasvinthe, en application d'une décision synodale, à bannir l'archevêque et à transférer la primatie de Séville à Tolède ${ }^{12}$. Il y avait donc eu transfert et le siège de la primatie d'E spagne, aux termes

7. Peter LINEHAN, «R eflexiones sobre historiografía... », p.102-103; « From chronicle to history... », p. 19; et plus complètement $H$ istory and the historians... , p. 356-379.

8. Chronicon, p. 52: «Incipit continuatio C hronicorum beati Isidori Archiepiscopi $\mathrm{H}$ ispalensis per beatum Illefonsum Archiepiscopum Toletanum composita ». Pour la double dignité d'I ldephonse: " H uc usque beatus scripsit Illefonsus H ispaniarum primas \& Archiepiscopus Toletanus... » (ibid., p. 55)

9. «Interfuit tunc dignitate primasille catholicus \& orthodoxus L eander $\mathrm{H}$ ispalensis A rchiepiscopus \& R omanae ecclesiae legatus... » (ibid., p. 50)

10. «R exit archipraesulatum $\mathrm{H}$ ispalensis ecclesiae quadraginta annis, diversis fulgens miraculorum signis, primatiae dignitate florens, \& R omani Papae in $\mathrm{H}$ ispaniis vices gerens » (ibid., p. 52).

11. "Iste a Romano Papa obtinuit privilegium, ut secundum beneplacitum pontificum $\mathrm{H}$ ispanorum, primatiae dignitas esset $\mathrm{H}$ ispali, vel Toleti... » (ibid., p. 55)

12. "Successit beatissimo doctori I sidoro Theodisclus natione G raecus, varietate lingvarum doctus, exterius locutione nitidus, interius autem, ut exitus demonstravit, sub ovina pelle lupus voracissimus. $\mathrm{N}$ am libros quosdam de naturis rerum $\&$ arte medicinae, necnon $\&$ de arte notoria, quos pater I sidorus facundo stylo composuerat, \& ne dum ad publicum venerant, in odium fidei corrupit resecans vera $\&$ inferens falsa: atque per quendam Arabum nomine Avicennam, de Latino in Arabicum transtulit. $\mathrm{H}$ ic in his \& alius pluribus infidelis inventus, \& erroneus in articulis fidei comprobatus, per Synodum ab Archiepiscopali dignitate degradatus est. A sserebat enim D ominum nostrum Jesum C hristum cum Patre $\&$ Spiritu sancto non esse unum Deum, sed potius adoptivum. $\mathrm{H}$ ic ut dictum est, privatus honore sacerdotii ad Arabes transiit: \& sectae pseudoprophetae $M$ ahometi adhaesit: \& plura docuit detestanda sub imperatore $\mathrm{H}$ eraclio. T unc temporis dignitas primatiae translata est ad ecclesiam Toletanam » (ibid., p. 53). Et un peu plus loin, p. 55: « [Chindasuinthus] perfidum Theodisclum H ispalensem episcopum Synodali sententia exulavit: $\&$ dignitatem primatiae transtulit ad ecclesiam Toletanam ». 
du privilège pontifical « obtenu »par Chindasvinthe, continuait de dépendre des délibérations d'un synode et de la force exécutoire d'un décret royal. D eux détails du règne, postérieur, de Wamba (672-680) et du concile au cours duquel il procéda censément à la division des évêchés hispaniques - Luc tient cette fois son récit de Pélage d'O viedo, luimême fort inventif ${ }^{13}$ - vont dans le même sens. $0 \mathrm{n}$ y voit en effet le roi décerner la primatie à Tolède « tant que cela plaira à la sainte assemblée » des évêques réunis à cette occasion ${ }^{14}$ et ordonner dans le même temps « qu'on ne soumette jamais à archevêque ou à primat la ville sacerdotale et royale de León $\gg^{15}$ dont il a déclaré au préalable qu'elle n'a jamais été « soumise à aucune métropole »16.

Lorsque dans les années 1243-1246, à l'avant-veille de la prise de Séville, Rodrigue de Tolède compose, sans doute à la demande du roi Ferdinand III, à qui il dédie son œuvre, I'H istoria de rebus $\mathrm{H}$ ispaniae ${ }^{17}$, le Chronicon de Luc figure parmi ses sources et sans doute est-il, parmi elles, celle que Rodrigue suit de plus près. $N$ on qu'elle lui paraisse la plus commode ni la plus autorisée. C'est que la chronique léonaise appelle, à chaque pas, le démenti; c'est que l'ouvrage est une véritable déclaration de guerre à la Castille, à Tolède et à son archevêque et primat. La documentation de l'épiscopat de Rodrigue révèle, au titre des dignités et des droits attachés à l'archevêché tolédan autant qu'à celui de ses possessions, un homme sourcilleux, conquérant et procédurier, porté par une agitation permanente ${ }^{18}$. Elle conserve une $\mathrm{N}$ otule de primatu, conçue vers 1240, dont Peter Linehan a magistralement montré qu'elle constitue une première réponse de Rodrigue aux thèses ecclésiologiques soutenues dans le Chronicon ${ }^{19}$. L'historien va se comporter comme le prélat et

13. Sur Pélage et ses forgeries, Javier FER NÁNDEZ CONDE, «Espacio y tiempo en la construcción ideológica de Pelayo de $O$ viedo », in: Patrick HENR IET (dir.), R eprésentations de $I^{\prime} e s p a c e$ et du temps dans I'E spagne des $\left|X{ }^{e}-X\right|||^{e}$ siècles. La construction de légitimités chrétiennes, à paraître dans les Annexes des $C$ ahiers de linguistique et de civilisation hispaniques médiévales, 15, 2002. 14. «Rex Bamba ut supra scriptum est, divisionibus Epantuum confirmatis, caeteras imperii sui sedes divisit, sic dicens: Toletum metropolis, regia sedes, inter caeteros $\mathrm{H}$ ispaniae quandiu huic sancto caetui placuerit, metropolitanos, teneat primatiam » (ibid., p. 56).

15. « Legio civitas sacerdotalis \& regia [... ] nulli unquam subdantur Archiepiscopo vel Primati » (ibid., p. 56).

16. «L egio [... ] alicui metropoli nunquam fuit subdita » (ibid., p. 56).

17. RODERICUS XIMENIUS de RADA, O pera (M aría de los D esamparados CABANES PEC OURT, éd.), Valencia: Anubar (Textos medievales, 22), 1985 [fac-similé de l'édition PP. Toletanorum de 1793]. Désormais, D e rebus.

18. MART IN, Les J uges de Castille... , p. 255-258. Également: Javier GOROSTERATZU, I nvestigaciones históricas sobre la E dad M edia. D on R odrigo J iménez de R ada, gran estadisqta, escritor y prelado, Pampelune, 1925 et surtout le très long « article » d'H ilda GRASSOTTI, «D on R odrigo X iménez de R ada, gran señor y hombre de negocios en la Castilla del siglo X III », Cuadernos de historia de E spaña, 55-56, 1972, p. 1-302.

19. P. LINEHAN, H istory and the historians... , p. 354-379. 
chaque offensive de Luc trouve dans le D e rebus sa réponse. Les armes, disons-le franchement, ne brillent guère par leur sophistication et l'affrontement - dans ses formes, sinon dans ses enjeux - tient par moments du combat de récréation. II révèle néanmoins un aspect peu étudié de l'usage des sources par l'historien médiéval: celui d'un texte choisi et suivi pour la seule raison que l'on en veut contredire systématiquement le propos ${ }^{20}$. Dans le $\mathrm{D}$ e rebus $\mathrm{H}$ ispaniae, Isidore, comme son frère Léandre, sont seulement qualifiés d'episcopi, et on les voit sièger sagement aux conciles présidés en règle par les primati tolédans ${ }^{21}$; le privilège pontifical obtenu par le roi Chindasvinthe arrête que, conformément aux vœux des évêques d'E spagne - Rodrigue reprend ici terme à terme le propos de Luc: « secundum beneplacitum Pontificum H ispanorum » - , la primatie ait son siège à Tolède « comme par le passé »22; la déposition de $" T$ héodiste ${ }^{23}$ de la chaire sévillane, très laconiquement rapportée - Rodrigue a évacué de son récit le développement sur les erreurs du mauvais archevêque et placé entre lui-même et Isidore, dont Luc le réputait le successeur, deux hommes (H onoré et Antoine) ${ }^{24}$

20. Sur ce qui suit, LINEHAN, ibid., p. 379-383. Sur ces usages historiographiques: G. M ART IN, H istoires de l'E spagne médiévale H istoriographie, geste, romancero, Paris: K lincksieck, 1997, p. 69-105 (« Paraphrase ») et 107-121 (« Compilation »).

21. «Sancti Leandri E piscopi » (D e rebus, II, 15, p. 40a), « [Sisenandus] anno regni tertio sui, LX V III G alliae et H ispaniae apud Toletum Episcopis congregatis cum absentium vicariis et palatii senioribus in Ecclesia Sanctae L eocadiae V irginis et M artyris C hristi, exstante adhuc I sidoro $\mathrm{H}$ ispalensi E piscopo, et in multis iam libris fulgente mirifice, de diversis causis $\mathrm{C}$ oncilium celebravit sub Iusto urbis regiae Primate, et subscribunt ibi Isidorus $\mathrm{H}$ ispalensis, Selva Narbonensis, Iulianus Bracarensis, etc. » (ibid., II, 19, p. 42b) et au-delà, pour d'autres évêques sévillans: "Sextum Concilium de observatione fidei catthicae et aliis ecclesiasticis disciplinis fuit tempore eiusdem Principis Cintilae celebratum sub Eugenio urbis regiae metropolitano et Primate, subscribentinus Selva Narbonensi, et Iuliano Bracarensi, et H onorato $\mathrm{H}$ ispalensi... » (ibid., II, 19, p. 43a), «In diebus huius anno quinto regni eius fuit octavum Concilium Toletanum, praesentibus et subscribentibus O rontio Emeritensi, Antonio H ispalensi, etc., sub Eugenio Toletano Pontifice et Primate sollemniter celebratum... » (ibid., II, 22, p. 45a), etc. Chaque concile est pour Rodrigue l'occasion de marteler la dignité primatiale des évêques tolédans: « et hoc fuit septimum Concilium Toletanum sub Eugenio metropolitano et Primati urbis regiae... » (ibid., II, 20, p. 43b), «[... ] istud fuit Concilium undecimum Toletanum sub Q uirico urbis regiae Primate » (ibid., III, 12, p. 58a), « Et hoc Concilium fuit sub Iuliano urbis regiae Primate... » (ibid., III, 13, p. 59b), « [ ... ] fuit celebratum septimum decimum Concilium Toletanum... sub Felice urbis regiae Primate... » (ibid., III, 14, p. 61a), etc.

22. " [C indasvindus] à Romano Pontifice obtinuit privilegium, ut secundum beneplacitum Pontificum H ispanorum Primatiae dignitas esset Toleti, sicut fuerat ab antiquo » (ibid., II , 21, p. 44b).

23. La « correction » du texte de Luc par Rodrigue ne manque pas ici de sel, puisqu'elle porte sur l'identité d'un personnage inventé par le L éonais et auquel, bien entendu, aucune autre source ne faisait référence. Elle pourrait, néanmoins, s'expliquer par le fait que Théodiscle était le nom - que Luc, au moins, n'avait pas inventé - d'un roi wisigothique ayant régné entre 548 et 549 (cf. Chronicon, p. 48 faussement numérotée 20).

24. De rebus, II, respectivement 19, p. 43 a et 20, p. $43 \mathrm{~b}$. 
à la tête de l'archevêché sévillan - , donne lieu - assez obscurément, du coup - à une « confirmation » par C hindasvinthe du rattachement traditionnel de la primatie d'E spagne à Tolède ${ }^{25}$. Q uant à la division des évêchés espagnols sous le règne de Wamba - qui, souvenons-nous, s'accompagnait dans le C hronicon de l'attribution de la primatie à Tolède par décision du roi et de la confirmation de l'indépendance de l'évêché léonais - elle disparaît purement et simplement du récit et se trouve substituée par deux décisions de sens contraire: la promulgation du décret «C um longe lateque » qui donnait à l'archevêque tolédan un droit de regard sur la nomination des évêques de toute l'Espagne et même de la $G$ allia et l'obligation pour les « évêques voisins » de demeurer un mois par an à Tolède ${ }^{26}$ (deux mesures qui avaient été prises, respectivement, aux douzième et septième conciles de Tolède, et nullement au onzième). Rodrigue ne pouvait rien contre l'existence du Chronicon mundi. Au moins maintenait-il l'alternative ouverte en laissant dans le $D$ e rebus $\mathrm{H}$ ispaniae une version contradictoire des faits. L'extrême lucidité de l'auteur quant à la concurrence que livrerait à son œuvre celle de Luc de T úy s'inscrit du reste dans sa construction: la version, si allusive qu'elle en devient incompréhensible, de la déposition de «T héodiste » et de la confirmation de la primatie tolédane par Chindasvinthe n'a d'autre explication que la compétition que pouvait livrer à Rodrigue la lecture éventuelle de l'œuvre de Luc. Pour plus de sûreté, Jimenez de Rada réfute encore par le menu, alors qu'il relate déjà les origines du royaume d'O viedo et à l'occasion d'une mise au point historique concernant le transport en Asturies de l' " arche des reliques », la thèse de ceux qui prétendent « quod primatus $\mathrm{H}$ ispaniae prius fuit in Ecclesia $\mathrm{H}$ ispalensi et post translatus ad Ecclesiam Toletanam $»^{27}$.

I rrévocablement opposés, le Chronicon mundi et le $\mathrm{D}$ e rebus $\mathrm{H}$ ispaniae furent, notamment pour la période gothique, que ces hommes prolongeaient jusqu'à eux ${ }^{28}$, les deux principales sources des historiens

25. « Hic perfidum Theodistum $\mathrm{H}$ ispalensem Episcopum Synodali sententia in exilium misit, et dignitatem Primatiae quam ab antiquo habuerat, totius approbatione $\mathrm{C}$ oncilii, Toletanae Ecclesiae confirmavit » (ibid., II, 21, p. 44b-45a).

26. «In hoc vero Concilio consolationem cum tantis viris recepit, et ibi fuit tunc illud Concilium constitutum [Cum longe lateque, et] ut vicini Episcopi singulis per annum mensibus in urbe regia debeant commorari » (ibid., III, 12, p. 58b et note marginale p); voir d'autres considérations chronologiques (à mon sens moins convaincantes) de LINEHAN dans H istory and the historians..., p. 381-383.

27. D e rebus, IV, 3, p. 78a.

28. Par exemple: «Por ende dexa aqui la estoria defablar delos sueuos et de los vuandalos et de los fechos que contescieron en E spanna et cuenta de los godos que fueron ende sennores despues aca todauia, como quier que ouieron y los moros yaquanto tiempo al gun sennorio », Estoire d'E spagne, R amón M ENÉNDEZ PIDAL (éd.), Primera crónica general de E spaña, 2 vol., M adrid: Gredos, 1955, 1, p. 215b. Sur cette représentation de la périodicité historique comme sur l'ensemble du modèle historio- 
d'Alphonse $X$ le Sage. Sous couvert de concilier le propos de leurs devanciers, ceux-ci, dans une adroite compilation, réduisirent leur discordance à leur principal intérêt: asseoir sur les leçons du passé la toute-puissance à laquelle aspirait désormais la royauté castillane ${ }^{29}$. Sous ce rapport, le traitement du thème primatial déploie un instructif échantillonnage des techniques qui caractérisent l'opération historiographique, le plus souvent fort ingénieuse, que l'on désigne de façon aussi courante que trop banale par le mot " compilation ». Entre L uc et R odrigue, les historiens alphonsins ne voient pas I'intérêt de trancher quant à la localisation de la primatie d'E spagne aux temps de Léandre et d'I sidore. Ils effacent ainsi le titre primatial que Luc attribuait aux deux frères et s'en tiennent à les qualifier d'archevêques - non d'évêques, toutefois, comme le faisait Rodrigue. Mais d'un autre côté, ils éliminent aussi les rappels par quoi R odrigue martelait, à chaque concile, la dignité primatiale de l'archevêque de Tolède: aucune évocation conciliaire ne donne lieu ici à la mention de la primatie. Supression, donc, de tous les marqueurs du débat, eussent-ils été l'œuvre du Tolédan ou du Léonais, mais dont l'effet majeur - le seul recherché - est de laisser chaque fois le roi, en majesté, appeler seul à la tenue du concile et le présider seul ${ }^{30}$. L e même objectif peut,

graphique alphonsin, G. M ARTIN, «EI modelo historiográfico alfonsí y sus antecedentes » in: G. MARTIN (dir.), La historia alfonsí: el modelo y sus destinos (siglos XIII-XV), M adrid: Collection de la Casa de Velázquez (68), 2000, p. 9-40 (sur ce point précis, voir p. 24).

29. Sur Alphonse $X$ le Sage et son entreprise historiographique, G. MARTIN, Les J uges de Castille..., p. 317-430; $\mathrm{H}$ istoires de l'E spagne médiévale. H istoriographie, geste, romancero, Paris: K lincksieck, 1997, p. 69-105, 107-121 et 123-136; et l'ouvrage collectif cité dans la note antérieure (abondante bibliographie p. 33-40).

30. R. M ENÉNDEZ PIDAL, Primera crónica general... , $1:$ « [E I rey L eovigildo] echo de la tierra a sant $L$ eandro arçobispo de Seuilla, e a $M$ ausona arçobispo de $M$ erida... » (p. 262b), « [... ] luego que començo a regnar [el rey Recaredo] enuio por sant $L$ eandro e sant $F$ ful gencio e por $M$ ausona, los arçobispos... » (p. 263b), « [... ] fizo este rey R ecaredo concilio en Tol edo, et estefue el III concilio, efueron en el sesaenta et dos obispos allegados de amas las E spannas pora destroyr et desarraygar la heregia arriana. D estos obispos fueron $M$ ausona arçobispo de $M$ erida, E uphimio arçobispo de Tarragona, sant L eandro arçobispo de Seuilla, M igestro arçobispo de N arbona e Partardo arçobispo de B ragana » (p. 264ab), « [... ] este rey Sisebuto fizo concilio en Seuilla sobre razon duna heregia que se mouiera dunas yentes que dizien acephalos. $E$ era estoncs arçobispo del logar sant E sidro; e un obispo que era daquellas yentes et deffendie aquella heregia, fue en aquel concilio, et uenciol sant E sydro por derecha razon, et tirol dell yerro en que estaua » (p. 272a), « [... ] fizo este rey Sisenando concilio en Tol edo en la eglesia de sancta L ocadia dell alcaçar, e ayunto y de tierra de $E$ spanna et de la $G$ allia $G$ othica sesaenta et ocho obispos, e fueron y los personeros de todos los otros que non uinieron. Et fizo ell este concilio con los mayorales de su regno. E uino y sant E sidro, arçobispo de Seuilla, el que auie y fechos muchos buenos libros et muchas escripturas. E ste concilio fue fecho por muchas cosas que eran a pro de la tierra, et pusieron en el muchos establescimientos buenos. $E$ era estonces arçobispo de Toledo don Yusto. E escriuieron y sus nombres sant E sydro arçobispo de Seuilla, eSclua arçobispo deN arbona, e) ulio arçobispo de B ragana, eAudax arçobispo de Tarragona e $Y$ miro personero dell arçobispo de $\mathrm{M}$ erida, $\mathrm{e}$ los obispos que eran sus sufraganeos » (p. 276a), «E ste rey Cintilla luego en comienço de su regnado, fizo concilio en Toledo; e este fue el quinto. E fueron en el XXIIII obispos. E era don E ugenio estonces arçobispo de Toledo. [... ] » (p. 276b), « [... ] fizo fazer este rey Cintilla el VI0 concilio en Toledo en que fue puesto 
au contraire, conduire les historiens d'A Iphonse le Sage à additionner les unes aux autres les données qui, chez leurs prédecesseurs, appartenaient à des systèmes inconciliables. Nul inconvénient, ainsi, à conserver dans l'évocation du onzième concile de Tolède les deux mesures favorables à l'archevêché dont Rodrigue prétendait mensongèrement qu'elles y avaient été prises ${ }^{31}$; mais la division des évêchés d'E spagne par Wamba, avec la concession par le roi de la primatie à Tolède, y reprend place elle aussi ${ }^{32}$. Et ce dernier fait, qui n'a que l'apparence d'être favorable à Tolède, se trouve réinséré dans la chaîne forgée par Luc de T úy pour la bonne raison que celle-ci, contre la tradition, exaltait le pouvoir du roi : le privilège pontifical obtenu par $C$ hindasvinthe avec l'assentiment des évêques d'Espagne autorise à nouveau le roi à choisir d'attribuer à Tolède ou à Séville la primatie d'E spagne ${ }^{33}$ et celuici, après avoir, en application d'une sentence conciliaire, mis un terme à l'épiscopat de Théodiste ${ }^{34}$, transfère, cette fois de son seul chef, de Séville à Tolède la primatie d'E spagne ${ }^{35}$. « R endit », écrivent plus exactement les compilateurs alphonsins, qui ajoutent: « comme elle l'avait eue par le passé ». La concession à Rodrigue est sans conséquence. C'est, pour des raisons proprement politiques, le système de Luc que suivent, sur le fond, les historiens d'Alphonse $X$ et ils vont même au-delà de Luc dans I'affirmation - que Ferdinand III, au plan des institutions,

como se deue guardar la fe catholica et otras cosas spiritales, seyendo don E ugenio arçobispo de Toledo. E escriuieron y sus nombres estos arçobispos: Sclua arçobispo de Narbona, J ulian de B ragana, $\mathrm{H}$ onorato de Seuilla, Prothasio de Tarragona, e los obispos de sos arçobispados et los uicariosq de los que non uinieran » (p. 277b), «E ste rey R ecesuindo luego en comienço de su regnado fizo concilio en Toledo; et este fue ell otauo concilio, efueron en el muchos omnes buenos, et escribieron y sus nombres 0 roncio arçobispo de $M$ erida, Antonio arçobispo de Seuilla, Potamio de B ragana, e los obispos que eran de sus arçobispados, e demas los obispos de las prouincias de N arbona et de Tarragona, seyendo $\mathrm{E}$ ugenio arçobispo de Toledo; e fueron por todos los obispos cinquaenta et dos... » (p. 280b), etc.

31. «E en aquel concilio fizieron el degredo que se comiença: cum longe lateque. $E$ fue puesto en aquel concilio otrossi que todos los obispos uezinos de Toledo que moren y una uez en ell anno al menos un mes... » (ibid., p. 299a). Les auteurs ajoutent: « ... mas esto non se touo nin se tien aun agora ». Voilà un propos qui ne semble pas émaner de la cathédrale de Tolède... L'affirmation de l'indépendance léonaise, du reste, est préservée: «E I obispado de L eon, que en otro tiempo fue llamado F lor, que por franqueza del apostoligo es libre pora siempre de toda subjection, et que siempre fue siella real daquellos que ante de nos uinieron et nunqua obedescio a arçobispo ninguno, tenga por terminos aquellos que siempre ouo et uso » (p. 295b).

32. I bid., p. 294b-298b. « La siella arçobispal de Toledo tenga el primado entre todos los otros arçobispados de E spanna » (p. 296b).

33. «E ste rey $C$ indasuindo luego en començo de su regnado enuio pedir all apostol igo un priuil egio tal, a plazer de los obispos de E spanna, que la dignidad del primado que fuesse en Toledo o en Seuilla, 0 el uiesse que era meior ; et el papa otorgogelo » (ibid., p. 278b).

34. «E desi fizo echar dell arçobispado de Seuilla por sentencia de concilio all arçobispo T heodisto... » (p. 278b).

35. «E t por esta razon torno el rey la dignidad del primado que auie la eglesia de Seuilla a la siella de Toledo, assi como la ouiera de antigo » (ibid., p. 279a). 
et Alphonse $X$ en pratique, avaient effectivement renforcée ${ }^{36}$ - du pouvoir d'intervention de la royauté sur la vie de l'Église.

Q uittons maintenant le terrain des disputes primatiales pour aborder plus directement l'espace des puissances laïques. Sur ce terrain, les hommes dont nous venons de faire rapidement connaissance laissent mieux apparaître les forces sociales, culturelles et mentales qui les meuvent.

\section{L'escarbougle de Saint-Đenis ${ }^{37}$}

D'où Luc de Túy tient-il ce récit? $\mathrm{Nul}$ ne le sait ${ }^{38}$. Son imagination vénéneuse s'exerce cette fois à l'encontre des Francs et des nobles laïques. C e sont, chez L uc, deux animosités constantes dont il partage la première avec d'autres représentants de la tradition historiographique léonaise ${ }^{39}$. Voici : Louis VII, roi de France, qui a épousé en secondes noces É lisabeth, fille d'A Iphonse VII de C astille et de L eón, « empereur des Espagnes», se voit suggérer par de mauvaises langues que sa femme est une bâtarde née d'une vilaine. Prétextant un pélerinage à Compostelle, il se rend en E spagne pour enquêter. La gloire et la munificence de l'empereur, la noblesse de ses grands vassaux, l'apparat de sa cour sauront le convaincre de la noble et légitime naissance de son épouse. II reviendra en France comblé d'honneur et déposera à Saint-Denis la splendide pierre précieuse (émeraude ou rubis) que lui aura offerte son beau-père ${ }^{40}$. L'évocation historique se construit sur quelques relations simples qui en font tout le sens. Aux Francs médisants et hypocrites (« quidam maligni detractores coeperunt Ludovici Regis Francorum auribus instillare... », «R ex turbatus, simulans se causa orationis ad sanctum Jacobum venire, venit in $\mathrm{H}$ ispaniam... »), s'opposent les $\mathrm{G}$ oths

36. Sur ce point, la synthèse de Joseph F. O 'CALLAGH AN, EI rey sabio. E I reinado deA lfonso $X$ de Castilla, Séville: U niversidad de Sevilla, 1996 (traduction de l'édition originale américaine, The Learned King. T he Reign of Alfonso X of Castile, Pennsylviana University Press, 1993), p. 77-94.

37. Pour une étude plus fouillée de l'épisode: G. M ART IN, «L'escarboucle de Saint-D enis, le roi de France et l'empereur des Espagnes » (réf. note 6). Je renvoie trop souvent à mes propres travaux, mais ce sont les seuls qui sur les sujets dont je traite ici soient écrits en langue française.

38. M ART IN, «L'escarboucle de Saint-D enis... », p. 451-453. Nulle trace de l'épisode dans I'historiographie espagnole non plus que française avant le Chronicon mundi.

39. Concernant la francophobie de Luc et, par exemple, celle de l'auteur de l'H istoria silensis (léonaise, en dépit de son titre, et datant d'environ 1150), ibid., p. 453 n. 45 et id., L es J uges de Castille... , p. 399 n. 108; voir également l'évocation très suggestive de P. H EN RIET, «X énophobie et intégration... », p. 39-43. Pour les convictions anti-nobiliaires du chanoine léonais, MARTIN, Les J uges de Castille... , p. 205-211.

40. Chronicon, p. 104-105. Texte complet: Annexes, 1. 
affairés à combattre les M aures (« Sed I mperator ut erat magnanimus dissimulans aegritudinem cum manu Gotthorum maxima contra M auros perrexit. Q ui ut viderunt cum magno exercitu, colla ei illico submiserunt »). L'intimité des laïcs, toujours suspecte («Elisabeth uxorem ejus I mperator A defonsus genuerat de vilissima concubina »), est forcée sans ménagement, même celle des rois (« D enegaverat etiam ei conjux ejus Elisabet thorum conjugalem, eo quod ita Rex Ludovicus improperabat sibi »). Les nobles sont magnifiques mais débordants d'audace: en menaçant le roi de France de son propre chef et en présence de son seigneur l'empereur des Espagnes (« comes R aymundus [... ] dixit L udovico Regi : $\mathrm{H}$ abeas in magno honore \& reverentia Elisabeth neptem meam, alioquin cum auxilio praesentis domini mei Imperatoris Adefonsi promitto me tibi Parisiis in parvo ponte campale inferre bellum »), le comte de Barcelone outrepasse ses prérogatives et empiète sur celles du roi. La première rencontre des deux souverains et le premier émerveillement des Francs ont lieu, bien entendu, à León (" Sed ubi Rex Ludovicus venit Legionem, occurrit ei Imperator Adefonsus cum tam glorioso apparatu, quod ipse Rex Ludovicus, \& Franci, qui cum eo venerant, obstupuerint »). Le thème de l'émeraude, associé à celui des grands sanctuaires, solidarise ces significations: le feint pèlerinage du roi des Francs à Saint-Jacques et ses sombres raisons contraste avec le pur éclat de l'émeraude gagnée par les $\mathrm{G}$ oths sur le roi maure Zaphadola et qui, offerte à L ouis par l'empereur des Espagnes, vient enrichir le trésor de Saint-D enis dont le temple recevra finalement la sainte dépouille d'une reine d'origine espagnole.

Rodrigue ${ }^{41}$ donne de l'antagonisme une vision territoriale - Espagne contre France - plus moderne et donc moins traditionnelle, moins marquée d'atavisme, que celle de l'affrontement ethnique posé par Luc. Elle est aussi moins défavorable à L ouis VII, qui cesse d'apparaître comme un benet extasié que l'on transporte ici et là. N otre historien, il est vrai, a étudié la théologie à Paris. II a visité Saint-D enis et s'empresse de le déclarer. Bien que la chose soit peu sensible dans ce passage, son œuvre et sa vie témoignent de ce qu'il a été séduit par le modèle d'une royauté féodale, assez conforme, finalement, à la tradition politique navarraise avec laquelle R odrigue, par son lignage paternel, était familiarisée ${ }^{42}$. Le Tolédan approche aussi plus respectueusement les personnes royales aucune allusion, ici, à l'intimité conjugale de l'empereur - et gomme avec bienveillance les excès de l'impétuosité nobiliaire - I'apostrophe du comte de Barcelone disparaît du récit au profit d'une évocation plus

41. De rebus, VII, 9, p. 154-155. Texte complet: Annexes, 2.

42. Sur I'idéologie politique du Tolédan, M ART IN, Les J uges de Castille... , p. 260-270. 
majestueuse: « Comitem Barcinonae, qui in magno et honorabili apparatu erat ». Q uant à l'espace où se déroulent les faits, la première rencontre a lieu à Burgos, ce qui a pour effet de circonscrire tout l'épisode dans les limites de la Castille, tandis que le voyage à Saint-Jacques, plus lapidairement expédié encore que dans le C hronicon, laisse toute la place à l'exaltation de la cour qui se tient à Tolède. Enfin, les traits de sainteté dont Luc parait Élisabeth ne sont plus ici de mise: sans doute contrariaient-ils l'idée que le très séculier archevêque se faisait d'une femme de roi. Soit: cette révision des faits imaginés par Luc témoigne à son tour des constantes mentales d'un homme issu de deux grands lignages de la noblesse, I'un navarrais l'autre castillan, farouche partisan de l'hégémonie de la Castille en Espagne, grand seigneur et même grand guerrier, convaincu de ce que l'harmonie politique du royaume repose sur un partage équitable du pouvoir entre la noblesse et la royauté.

À partir de cet épisode, notre lecture comparative des traitements historiographiques d'un même fait devra suivre, pour les héritiers de Luc et de Rodrigue, plusieurs voies qui sont celles de deux voire de trois versions de l'E stoire d'E spagne qui divergent dans leur sens. L'univocité de l'œuvre, en effet, ne se prolonge que jusqu'à la dix-septième année de règne d'A lphonse II de León (791-842). Au-delà, la tradition textuelle ${ }^{43}$, nullement arrêtée par un manuscrit royal, offre deux variantes principales: une version dite " concise », achevée peu après 1270, et une version dite "critique ", conçue dans les dernières années du règne d'Alphonse X, aux environs de 1283. La version concise, hélas, nous est parvenue sous forme très lacunaire et aucun des manuscrits qui la conservent ne contient l'épisode qui nous intéresse. En revanche, cinq ans à peine après la mort d'Alphonse $X$, sous le règne de son fils et successeur Sanche IV (1284-1295), une troisième version, dite « amplifiée », voit le jour. Version « critique » et version « amplifiée » s'inspirent, indépendamment l'une de l'autre, de la version « concise ». Comme pour l'affaire de la primatie d'Espagne, les nouveaux histo-

43. Sur la tradition textuelle de l'E stoire d'E spagne: Diego CATALÁN, D eAlfonso $X$ al conde de Barcelos. cuatro estudios sobre el nacimiento de la historiografía romance en $C$ astilla y Portugal, $M$ adrid: Gredos, 1962; La "E storia de E spaña » de Alfonso X. Creación y evolución, M adrid: Fundación Ramón M enéndez Pidal/ U niversidad Autónoma de M adrid, 1992; D e la silva textual al taller historiografico alfonsí. Códices, crónicas, versiones y cuadernos de trabajo, M adrid: Fundación Ramón M enéndez Pidal/ U niversidad Autónoma de Madrid, 1997. Sur la version critique: Inés FER N ÁN D EZ-O R DÓ ÑEZ, Versión crítica de la «E storia de E spaña » (estudio y edición desde Pelayo hasta Ordoño (I), M adrid: Fundación Ramón M enéndez Pidal/ U niversidad Autónoma de M adrid, 1993; et «La historiografía alfonsí en sus textos. Nuevo panorama », Cahiers de linguistique hispanique médiévale, 18-19, 1993-1994, p. 101-132. Interprétation des versions: I. FER NÁNDEZ-ORD ÓÑEZ, «Evolución del pensamiento alfonsí y transformación de las obras jurídicas e históricas del R ey Sabio », C ahiers de linguistique hispanique médiévale, 23, 2000, p. 263-283. En français: M ART IN, Les J uges de Castille... , p. 328-383. 
riens, par des mélanges subtilement dosés et d'adroites interventions, amènent les propos de Luc et de R odrigue à servir leur propre doctrine. Or, les nuances qui distinguent la version « critique » et la version « amplifiée » - le phénomène sera plus net encore dans le dernier épisode que nous étudierons - ne semblent pas sans rapport avec ce qui mettait à distance les agencements de Luc et de R odrigue. L a première, il est vrai, est écrite à Séville, tandis que la seconde est une création de la cathédrale de Tolède.

A Séville, les auteurs de la version dite « critique » de l'E stoire d'E spagne $^{44}$ - je l'appellerais volontiers « version al phonsine sévillane » - travaillent dans de bien pénibles circonstances. La noblesse, la plus grande partie des prélats, les villes même, groupées derrière Sanche, héritier présomptif, viennent de se soulever contre A Iphonse. L e roi est seul dans Séville, confronté au délabrement de son autorité et de sa santé, en guerre contre tous, raidi sur les valeurs régaliennes qu'il exalte plus que jamais dans les dernières révisions de ses œuvres ${ }^{45}$. Les historiens alphonsins conservent de Rodrigue le centrage castillan de l'épisode et la définition territoriale de l'antagonisme, deux traits parfaitement ajustés à l'idéologie politique à la fois « naturaliste » et castillano-centriste d'Alphonse $X^{46}$ : la confrontation oppose la France et I'Espagne et la première rencontre a lieu à Burgos. De même, ils respectent comme le faisait R odrigue de scrupuleuses bienséances à l'endroit des personnes royales: dans leur récit, nulle péripétie d'alcôve. En revanche, et cette fois fidèlement à Luc, la censure implicite de certains comportements nobiliaires demeure - le comte de Barcelone continue d'aller trop loin et surtout - ce point relevait, bien entendu, d'un enjeu majeur du règne - la dimension impériale d'Alphonse VII et de sa femme I'« impératrice » Bérengère, qui revient dans le récit, est continûment soulignée au

44. M anuel ALVAR et al., Crónica de veinte reyes, Burgos: Excelentísimo Ayuntamiento, 1991, p. 264-265. Texte complet traduit en français: Annexes, 3.

45. Sur cette fin de règne, J. O'CALLAGHAN, EI Rey Sabio..., p. 281-320. Quant à I'atmosphère idéologique, pour les œuvres juridiques: M ART IN : «Alphonse X ou la science politique (Septénaire, 1-11) », Cahiers de linguistique hispanique médiévale, 18-19, 1993-1994, p. 79-100 et 20, 1995, p. 7-33 ainsi que «Alphonse X maudit son fils », Atalaya, 5, 1994, p. 153-178; pour l'historiographie: FERNÁN DEZ-O RDÓÑEZ, «Evolución del pensamiento alfonsí... » et « Variación en el modelo historiográfico alfonsí en el siglo XIII. Las versiones de la E storia de E spaña », in : La historia alfonsí... (M ART IN, dir.), p. 41-74.

46. Sur la doctrine politique d'Alphonse $X$ et notamment sur le concept fondamental de «naturaleza »: M ARTIN, L es J uges deC astille... , p. 317-338; « Alphonse X ou la science politique... »; " Alphonse $X$ roi et empereur. Commentaire du Titre 1 de la Seconde partie », Cahiers de linguistique hispanique médiévale, 23,2000, p. 323-348. Le « naturalisme » politique, qui s'enracine philosophiquement dans l'aristotélisme chrétien, a pour principal objet de donner de la dépendance une définition prioritairement territoriale, tenant à l'espace politique où naît ou bien vit habituellement le sujet (le « natural », dans cette doctrine anti-féodale). L e premier « seigneur naturel » du royaume est, bien entendu, le roi. 
détriment du rang seulement royal de Louis VII de France. U ne évaluation générale, que nos historiens ont trouvée dans un autre passage du Chronicon ${ }^{47}$ et qu'ils ont transférée ici, parachève ce portrait impérial en rappelant la tutelle féodale dans laquelle «l'E mpereur » maintint les souverains environnants, navarrais, catalano-aragonais et maures. Le portrait d'É lisabeth en sainte, qui, par métonymie, auréolait de sainteté la royauté castillane, n'est pas censuré. La couronne « de l'épine », reliquaire en forme de couronne dont un grenat percé était censé contenir une épine de la couronne qui avait ceint le front du C hrist ${ }^{48}$ est ici remplacée, pour plus de sacralité encore, par la « couronne desépines » tout entière, achetée naguère par L ouis IX à l'empereur de Constantinople. N ous sommes au plus fort d'une exaltation de la $C$ astille parmi les puissances politiques et spirituelles du monde, $\mathrm{O}$ ccident et $\mathrm{O}$ rient confondus, au plus fort d'une exaltation de l'aura impériale de la royauté castillano-léonaise. Sur le fond, les officiers sévillans d'A Iphonse $X$ sont plus près de Luc que de Rodrigue.

La version « amplifiée » - que j'appelle "version sancienne tolédane » - de l'E stoire est composée vers 1289 dans une conjoncture plus souriante mais où les ombres, pourtant, ne manquent pas. Sanche IV a imposé son droit et préservé l'unité du royaume ${ }^{49}$. M aisil a été porté sur le trône par la déferlante de la sédition et un mariage consanguin menace les droits de sa descendance ${ }^{50}$. Autour du roi et de $M$ arie de M olina, autour de l'archevêque de Tolède G onzague Pérez G udiel et de son chapitre, avec le concours de quelques lignages de la noblesse et l'appui constant et résolu, en deniers et en hommes, des villes de Castille, se met en place une pratique politique et une doctrine reposant, d'une part, sur l'accord que scelle la couronne avec les « états » (Église, noblesse et villes) dans le respect des fonctions et des traditions de chacun et, d'autre part, sur une forte exaltation de la royauté et de la patrie. Les auteurs de la version " amplifiée » appartiennent au chapitre tolé dan, à l'école-cathédrale ou à ses satellites: Rodrigue est cité à tout propos et l'archevêque primat de Tolède fait, ici comme à l'occasion d'autres nombreux épisodes, sa première apparition dans le récit. Pour l'essentiel, la version qu'ils produisent des faits ${ }^{51}$ n'est guère éloignée de la précédente: antagonisme territorial, centralité castillane du royaume,

47. Chronicon, p. 104 : «Tantum illi... oppressis pauperibus contulit ».

48. B. de MONTESQUIOU-FEZENSAC et D. GABORIT-CHOPIN, Le trésor de SaintD enis, 3 vol., Paris, 1977, 3, p. 106-108.

49. G. MARTIN, «Alphonse $X$ maudit son fils» (réf. note 45).

50. Id., Les J uges de Castille, p. 461-463 et 543-544.

51. MENENDEZ PIDAL, Primera crónica general de E spaña (réf. note 28), 2, p. 656-658.

Texte complet traduit en français: Annexes, 4. 
hégémonie impériale de la C astille en Espagne. Trois choses diffèrent, néanmoins: I'intervention intempestive du comte de Barcelone est bannie de l'épisode - ce qui obéit au système narratif et idéologique de R odrigue -, la dimension impériale d'Alphonse VII et celle de sa femme - pour la première fois dotée en propre d'une cour - sont plus que jamais rehaussées, le couple impérial, enfin, se trouve environné d'une É glise et surtout d'une noblesse chevaleresque à la fois prospères, ordonnées et domestiquées dont les bénéfices qu'elles tirent de la couronne et I'appui qu'elles lui apportent en retour fondent au tout premier chef avec des villes dont l'artisanat et le commerce laissent percevoir en filigrane la splendeur - la magnificence qui éblouit L ouis V II de France. Le thème dionysien amplifie encore, au plan spirituel, le rayonnement de l'Espagne: c'est ici dans la couronne même de Jésus-C hrist que l'escarboucle espagnole - « une escarboucle qui était de celles qui furent en la couronne d'épines que l'on posa sur la tête de Jésus $C$ hrist le jour de sa passion »! - puise une valeur sacrée devenue intrinsèque, tandis que Saint-D enis, privé de C ouronne d'épines, se borne désormais à recevoir dans son reliquaire le précieux joyau christique donné par l'empereur. Le molinisme tolédan emprunte à Luc et à Rodrigue. Sur les pas de Luc, et allant même au-delà, il se fait le chantre de la grandeur hispanique et de la dimension proprement hispanique du pouvoir d'Alphonse VII. II conserve néanmoins de Rodrigue, et même exacerbe l'idée que l'ordre royal repose, non sur un concentration régalienne du pouvoir, mais sur l'entente harmonieuse de la couronne avec la noblesse et, plus accessoirement, avec l'É glise et avec les villes, sur le dévouement que la première peut espérer des secondes à la condition de respecter leurs prérogatives et d'assurer leur prospérité. De Rodrigue au molinisme de G onzague Pérez Gudiel, d'un archevêque tolédan à l'autre, il existe une solide continuité. C elle-ci est plus nette encore dans l'épisode, entre tous politique, quej'ai gardé pour la fin.

\section{L a LÉGende des Juges de C Astille 52}

L orsqu'elle parvient à L uc de T úy - à travers le Liber regum navarrais ou sa traduction tolédane ${ }^{53}$-, la légende des Juges de Castille tient en quatre phrases:

[Le roi Alphonse II le Chaste] ne laissa aucun fils, il ne resta aucun homme de son lignage pour maintenir la royauté et la terre resta longtemps ainsi.

52. Sur tout ceci M ART IN, Les J uges de Castille..., p. 25-430.

53. Ceci pourrait être un indice de plus de l'existence, dont Peter $L$ inehan concevait dans ce même colloque I'hypothèse, d'échanges d'informations entre Luc et R odrigue à la veille de la rédaction du Chronicon. 
Puis les hommes s'accordèrent et élirent deux juges [pour chefs]. L'un eut nom Nuño Rasura, l'autre Laïn Calvo. Du lignage de Nuño Rasura vint l'empereur de Castille et du lignage de Laïn Calvo vint M on Cid le Campéador ${ }^{54}$.

Au vrai, et malgré sa brièveté, cette légende inventée à l'initiative des hommes qui, à partir de 1134, s'employèrent à restaurer et à maintenir contre vents et marées la royauté navarraise, bouleversait, par ses implications, I'histoire des royautés d'E spagne. D estinée à mettre sur un pied d'égalité les souverains castillans - réputés descendre de N uño R asura et les nouveaux rois de $\mathrm{N}$ avarre - descendants effectifs du Cid (et de I'imaginaire Laïn Calvo) - , elle faisait remonter la légitimité des rois de Castille non plus aux W isigoths, dont les coupait censément la mort sans postérité d'A Iphonse II (791-842), mais à l'élection de deux Juges inventés pour la circonstance $e^{55}$.

Luc ${ }^{56}$ ne pouvait accepter que l'on coupât ainsi les racines léonaises, seules légitimantes, à son sens, de la royauté castillane. $M$ ais il comprit

54. Louis CO O PER, EI Liber regum. E studio linguístico, Saragosse: Institución Fernando el Católico, 1960, p. 33. Biblioteca U niversitaria de Zaragoza, ms. 225, fol. $33 \mathrm{r}^{\circ}$ : «E st rei don alfonso. no(n) lexo fillo ne(n)guno. ni no(n) remaso om(n) e de so lignage q(u)e mantouiesse el résmo \& estido la tierra assi luengos tiempos. E pues acordoronse. \& eslieron dos iudices [dans la marge: porques cabdelassen destos dos iudices]. el uno ouo nomne nunno rasuera. \& el otro ouo nomne lain calbo. Del lignage de nunno rasuera. uino lemperador de castiella. E del lignage de lain calbo. uino mio cith el campiador ». Le L iber est traduit à Tolède vers 1220 à la demande de Rodrigue J imenez (M ARTIN, Les ) uges de Castille..., p. 70, 83 n. 18 et 105 n. 128).

55. MARTIN, Les J uges de Castille... , p. 27-194.

56. Chronicon, 4, p. 82-83: «Era DCCCCLXI. Froylanus frater eius O rdonii successit in regnum $\&$ duxit uxorem nomine $M$ uma domam, ex qua hos filios habuit, A defonsum, 0 rdonium, \& R amirum. H abuit etiam filium nomine Aznarem de concubina. R ex Froylanus nihil memorabile gessit propter paucitatem dierum, nisi quod filios 0 Imudi nobilis sine culpa trucidare jussit, \& fratrem eorum Frominium Legionensem episcopum sine culpa in exilium misit. Justo Dei judicio Froylanus regno caruit, quia innocuos occidit $\&$ Christum Domini episcopum Frominium contristavit. N on audivit D ominum per $\mathrm{D}$ avid dicentem, nolite tangere Christos meos, \& in prophetis meis nolite malignari. O b hoc abbreviatum est regnum eius, \& percussus lepra vitam finivit \& sepultus est in Legione iuxta fratrem suum Regem O rdonium. Regnavit anno uno mensibus duobus. Praefatus autem episcopus episcopatum suum tunc recuperavit. Rege Froylano vivente nobiles de $C$ astella contra ipsum tyrannidem sumpserunt, eum Regem habere nolentes. Elegerunt autem sibi duos iudices nobiles milites, id est N unnum R asoiram de $C$ atalonia $\&$ Jainium Calvum Burgensem, qui noluit suscipere iudicatum. N unnus vero R asoira ut erat vir sapiens petivit ab omnibus $\mathrm{C}$ omitibus $\mathrm{C}$ astellae, ut darent sibi filios suos nutriendos. $\mathrm{H}$ abebat ipse filium nomine $\mathrm{G}$ undisalvum, quem cum aliis nobilium filiis educavit. Sapienter se gessit N unnus Rasoira in judicatu suo, \& totam Castellam usque flumen de Pisorga iudicavit dum vixit. Tunc enim angustatum est regnum Legionense $\&$ in praedicto flumine metam fecit. H unc simplicem militem Castellani nobiles super se judicem erexerunt, ne si de nobilioribus suis judicem facerent, pro Rege vellet in eis dominari. Post mortem autem N unni R asoirae nobiles ab eo nutriti filium eius $G$ undisalvum $N$ unni, sibi judicem fecerunt; $\&$ etiam Comitem vocaverunt, dantes ei pro uxore $X$ emenam nobilissimam filiam Nunii Fernandi, ex qua filium habuit nomine Fernandum. Praedictus autem $G$ undisalvus N unni fuit sententia justus $\&$ armis strenuus \& multa bella intulit regno Legionensium \& Sarracenis. ad gesta veniamus. Era DCCCCLX III. mortuo Rege Froylano 
néanmoins tout le bénéfice que l'on pouvait tirer d'un récit qui, pour peu qu'on le remaniât, serait le parfait emblème des origines illégitimes de la sécession castillane et révélerait au mieux les forces qui en avaient décidé - celles-là mêmes qui, naguère encore, sous la minorité d'Alphonse V III et même aux premiers temps du règne de Ferdinand III en Castille, avaient agité les royaumes ${ }^{57}$. En situant l'événement à l'époque du méchant Fruela II (924-925), dont la Providence même avait écourté les jours, Luc, d'un seul coup, rétablissait la continuité royale léonaise, rendait les causes de l'élection des juges circonstancielles et transformait celle-ci en un acte «tyrannique » (« nobiles de C astella [... ] tyrannidem sumpserunt »). Les effets de l'institution des Juges se trouvaient du reste anéantis par le retour des Castillans, moins de dix ans plus tard, dans la sujétion des rois de L eón après que $R$ amire II les avait aidés à vaincre les $\mathrm{M}$ aures à $\mathrm{O} \mathrm{sma} \mathrm{a}^{58}$. Luc, surtout - l'importance donnée à la qualification sociale des personnages est aussi une nouveauté introduite par notre historien dans la tradition historiographique espagnole - , s'enquit de donner un statut social aux acteurs de l'élection et de qualifier leur comportement politique. Les rebelles avaient été les « nobiles » castillans et les juges élus de simples « milites », placés là pour leur faiblesse par des grands inquiets de ce qu'aucun des leurs ne s'emparât d'une puissance comparable à celle des rois: « ne si de nobilioribus suis judicem facerent, pro Rege vellet in eis dominari ». Enfin, par un rigoureux monarchisme, Luc abolit dès l'origine la dyarchie imaginée par les historiens navarrais et montre, en une génération, le régime de l'instauration du pouvoir suprême passer de l'élection à la succession héréditaire. Laïn Calvo, sans raison (« noluit suscipere iudicatum ») et comme par I'opération d'une Providence veillant au triomphe de la monarchie, renonce à sa charge et laisse $\mathrm{N}$ uño $\mathrm{R}$ asura installer à la tête des $\mathrm{C}$ astillans - par le « sage » subterfuge de l'éducation à sa cour, autour de

A defonsus filius R egis domini O rdonii, adeptus est regnum paternum... ». A nalyse plus complète dans M ART IN, Les J uges de Castille... , p. 201-249. O n imagine comment les Castillans devaient percevoir l'origine catalane que Luc prêtait au premier ancêtre de leurs rois (et la démission du juge burgalais).

57. M ARTIN, Les ) uges de Castille..., p. 207-211.

58. Chronicon, p. 83: «L egione vero (R amiro) sedente cum Sancia R egina nuncius venit quod A ceyfa cum grandi exercitu M aurorum properabat ad Castellam. Q uo audito Rex Ramirus immemor malorum quae sibi fecerant nobiles $C$ astellani cum exercitu magno obviam Sarracenis evixit, \& in loco qui dicitur O xoma nomen Domini invocando acies ordinare iussit, \& omnes se ad bellum parare. Dedit illi Dominus victoriam: \& magnam partem ex Sarracenis interfecit, \& multa millia captivorum secum abduxit $\&$ ad propriam sedem reversus est cum magna gloria. Tunc Castellani Ramiro Regi iura propria cognoscentes ei se subdiderunt. Tamen conditionis quasdam R ege concedente vendicaverunt ei ». Cette soumission est une invention de Luc. Elle ne figurait pas dans la Chronica silensis, qui est ici sa source (M ARTIN, Les J uges de Castille... , p. 238, n. 60). 


\section{Gonzague N uñez, des fils de la noblesse - un lignage promis à exercer le pouvoir royal en Castille. \\ Rodrigue ${ }^{59} n^{\prime}$ avait rien contre la royauté. $M$ ais il n'avait rien non plus contre la Castille ni contre la noblesse. Dans son récit, c'est le roi Fruela}

59. De rebus, V, 1, p. 97a-100a: « Liber quintus. De Froila et iudicibus. Cap. I. Post mortem O rdonii, Froila frater eius successit in regno. Aera DCCCCXXXII, et regnavit anno uno, mensibus duobus, et duxit uxorem nomine M unina D omna, ex qua suscepit tres filios, A defonsum, $\mathrm{O}$ rdonium, et $\mathrm{R}$ animirum, et quartum de concubina nomine $\mathrm{A}$ cenare. $\mathrm{H}$ ic nihil egit memoria dignum, nisi quod filios $\mathrm{O}$ Imundi nobilis sine culpa aliqua fecit occidi, et Fronimium, fratrem eorum, Legionsensem Episcopum exilio condemnavit; et quia viri impii non dimidiant dies suos, percussus lepra, unius anni et duorum mensium expleto circulo, vital finivit, et iuxta fratrem suum O rdonium Legione ingloriosus sepelitur. Episcopus Fronimius statim fuit sedi propriae restitutus. E isdem diebus nobiles Barduliae quae nunc $C$ astella dicitur, attendentes nobiles suos N unium Fernandi, Almondar A lbum, et filium eius Didacum vocatos ad colloquium ex factione à Rege 0 rdonio interfectos, tyrannum etiam Froilam, et multa alia quae, eis euntibus ad iudicium, à Regibus et magnatibus Legione iniuriose fiebant; videntes etiam quod termini gentis suae ex omnibus partibus arctabantur, et pro iudicio contemptus et contumelias reportabant, sibi et posteris providerunt, et duos milites non de potentioribus, sed de prudentioribus elegerunt, quos et iudices statuerunt, ut dissenssiones patriae et querelantium causae eorum iudicio sopirentur. U nus fuit N unius N unii, dictus R asuera, filius N unii Bellidez: alter deciebatur Flavinus Calvus; iste tamen aut nil, aut parum de iudiciis cagitabat, sed armis et militiae insistebat: erat enim facile iracundus, nec causarum varia pacifice sustinebat, quod non competit iudicanti. Ex huius genere processerunt multi et alii magni nobiles de $\mathrm{C}$ astella. [Suit la descendance de Laïn Calvo] De Nunio Rasura et filiis eius. Cap. II. Nunius autem cognomento R asura, fuit vir patiens et modestus, sollers et prudens, industrius, circunspectus, et sic ab omnibus amabatur, ut vix esset cui eius iudicia displicerent, aut eius sententias causaretur, quas tamen rarissime proferebat, quia in compositione amicabili fere omnia terminabat; et sic carus ab omnibus habebatur, ut locus aliquis detractioni, vel invidiae non peteret. $\mathrm{H}$ ic habuit filium nomine $\mathrm{G}$ undisalvum N unii, qui cum esset adolescens, bona indole coaetaneis praeminebat, et futurorum indiciis omnibus complacebat. N unius vero pater eius fere ab omnibus $C$ astellae militibus domicellos filios petiit nutriendos, quoscurialitate, affabilitate, et bonis moribussic instruxit, ut patres adolescentium de profectu filiorum profiterentur se tali nutricio obligatos; et ipsi adolescentes sic erant G undisalvo N unii dilectione coniuncti, ut eum quasi dominum sociarent, nec possent ab eius consortio vel ad modicum separari. Cumque crevisset factus miles, militiam strenuus exercebat, et pacis dulcedinem in patria retinebat, ita quod patre suo mortuo, patri fuit favore omnium substitutus, et etiam principatum militiae, conniventibus iis qui secum nutriti fuerant, addiderunt; et duxit uxorem noblissimam: Semenam nomine, filiam N unii Fernandi, ex qua suscepit filium nomine Ferdinandum. $\mathrm{H}$ ic fuit omnibus patre carior, in sermone verax, in iudicio iustus, in militia gloriosus; multa enim strenue contra A rabes peragendo, fines patriae ampliavit. Hic habuit filium qui dictus est Ferdinandi Gundisalvi. H unc D eus supra patrem et avum tot gratiis exaltavit, ut ipso non attedente, tam à magnatibus et militibus, quam ab universis populis C astellanis in Comitem crearetur, et omnes se suae subiicerent ditioni. Q ui factus $C$ omes, totam Castellam sic pacifico dominio confovebat, ut omnes $D$ eo gratias agerent, qui per talem Comitem a populo suo relevaverat sarcinam servitutis. Hic contra Arabes plurima bella gessit, quoniam et Sanctum Stephanum et alia plurima loca christianae restituit ditioni. Ex quo iste suscepit suae patriae Comitatum, cessaverunt R eges A sturiarum insolescere in Castellam, et à flumine Pisorica nihil amplius vindicaverunt: strenuitate enim sua eorum insultibus resistebat, nec propter eos à bellis Arabum desistebat. M onasterium Sancti Petri in ripa A slantiae fluminis aedificavit, et multis possessionibus illud dotavit. M orte propria defunctus, in eodem monasterio est sepultus: cui successit filius eius $G$ arsias Ferdinandi [suit la géné⿴囗ogiedu pouvoir comtal castillan jusqu'au mariaged'E Ivire, filledu comte Sanche, avec SancheleG rand deN avarre, union dont naîtra Ferdinand $I^{\otimes}$ de Castille] ». Pour une analyse plus complète, M ARTIN, L $\odot$ J uges de Castille... , p. 251-316. 
- à la suite de son frère 0 rdoño II et d'autres nombreux rois de L eón qui est «tyrannique » («tyrannum etiam Froilam ») et les Castillans, harcelés sur toutes leurs frontières et en butte aux injustices de la cour royale de L eón, prennent une véritable mesure de salut public en élisant des juges - non un roi - pour les gouverner. De même, le statut hiérarchique subalterne des élus est ici moins clair, ou en tout cas moins marqué, au sein d'une aristocratie perçue désormais comme un regroupement fonctionnel de « milites » - les jeunes gens que Nuño Rasura souhaite élever à sa cour ne sont plus, par exemple, les « Comitibus C astellae filios » ni des «nobiles», mais « fere ab omnibus Castellae militibus domicellos filios». La partition hiérarchique «nobiles» / «milites», sur quoi reposait la proclamation anti-nobiliaire de Luc est ainsi anéantie et l'épisode illustre au contraire la sagesse des « nobiles », chefs naturels des C astillans, qui sont assez avisés pour choisir les plus « prudents » et non, favorisant les leurs, les plus « puissants » des « milites »: « duos milites non de potentioribus, sed de prudentioribus elegerunt ». Du coup, ce n'est plus la méfiance et l'astuce qui rassemblent autour de $\mathrm{N}$ uño R asura et de son fils les jeunes nobles de Castille, mais un authentique souci d'éducation qui, du reste, suscite en retour obligation et amour. Q uant à la réduction monarchique de la dyarchie primitive, elle tient ici au tempérament de Laiin C alvo. Ancêtre des grands lignages de C astille et trop habité par la fougue des guerriers pour se pencher avec sérénité sur la complexité des causes venues devant lui, c'est à la fonction militaire et à la défense du territoire qu'il consacrera ses efforts, laissant à N uño R asura I'entier de la fonction judiciaire. Ici aussi, la Providence veille. $D$ ans les descendants de $N$ uño se conjugueront les vertus de justice et de vaillance, $G$ onzague N uñez et plus encore Ferrand $G$ onzalez préfigurant ainsi une royauté issue de la délégation au détenteur du pouvoir judiciaire d'un pouvoir militaire originellement dévolu à I'ancêtre des guerriers. M ais si, comme dans le C hronicon mundi, le cours de l'histoire est, dans le $\mathrm{D}$ e rebus $\mathrm{H}$ ispaniae, favorable à la monarchie, la royauté ne s'y trouve pas moins - comme dans l'éternité, dans l'essentialité du mythe - à jamais accompagnée d'un partenaire politique, indispensable à son émergence et à sa pérennité: la « militia ». Cette conviction du Tolédan détermine même le comportement judiciaire de Nuño Rasura: à la sentence, celui-ci préfère la conciliation amiable, mieux perçue par la noblesse. Q uant au fil de l'histoire, nulle rupture, bien entendu, après $0 \mathrm{sma}^{60}$ : des Juges à l'instauration d'une royauté

60. D e rebus, p. 101a: «Post haec A rabes fines $C$ astellae invadere decreverunt, et $C$ omes Fernandus $\mathrm{G}$ undisalvi, qui $\mathrm{C}$ astellae tunc temporis praesidebat, nunciavit adventum Arabum Ranimiro, qui convocato exercitu, properavit in auxilium Comitis Castellani. Cumque Legionensis et Castellanus exercitus convenissent, Arabibus apud oppidum Oxomam 
proprement castillane, le récit de Rodrigue déroule continûment une lignée qui mène aux comtes puis aux rois ${ }^{61}$.

Le corpus roman, alphonsin et néo-alphonsin, offre, cette fois, trois versions de l'épisode ${ }^{62}$. A ssociant les récits de Luc et de R odrigue sur des points cruciaux, ajoutant, aussi, ou expurgeant leurs sources souvent aux mêmes fins, celles-ci présentent de nombreux traits communs. La légitimation de la dissidence castillane, la portée salvatrice de l'instauration de la magistrature, la motivation publique des nobles sont toutes les trois reprises du Tolédan. D'un autre côté, I'observation critique du Léonais est maintenue: la méfiance envers leurs penchants dominateurs n'est pas étrangère au fait que les nobles castillans choisissent de simples chevaliers. De ces prémices, toutefois, disparaît la notation, à tous égards gênante, d'une " tyrannie » prêtée soit à la noblesse de Castille soit à Fruela II, tous deux liés in fine à la genèse de la royauté castillane. $\mathrm{Q}$ uant au « nobiles milites » qui qualifiait dans le Chronicon mundi le statut social des juges - I'auteur écrivait aussi, à propos de N uño Rasura, «simplex miles »-, il est sublimé, les juges étant désormais perçus comme des ancêtres du roi, en un « très nobles et de haut lignage » que l'on attribue du reste faussement à L uc. Enfin, I'inter prétation fonctionnelle que faisait R odrigue du renoncement de Laîn Calvo est reconduite. Les implications doctrinales quant à la consitution du pouvoir royal en étaient, au fond, assez ambiguës: fallait-il penser que la royauté n'existait que parce que la noblesse voulait bien mettre conditionnellement entre ses mains la puissance militaire qu'elle possédait par nature ou bien, au contraire, que la noblesse avait, à l'occasion de la remise du « principatum militiae » à Gonzague Nuñez, renoncé pour toujours à détenir la maîtrise des armes au profit de la royauté? Au total, on voit bien, sur le fond, se dessiner une interprétation fortement régalienne: elle impose une forme de « bienséance » imaginaire qui préserve, depuis les origines obscures et conflictuelles, l'image historique de la royauté, reconnaît les mérites de la noblesse en même temps qu'elle n'en ignore pas les

occurrerunt, et collatis signis, adinvicem dimicarunt, sed Dei gratia adiuvante, Christianis victoria, Arabibus cessit fuga, multaque millia captivorum christiano exercitui provenerunt. Sicque Rex R animirus ad sua feliciter est reversus ». N ulle mention du magnanime oubli de R amire, nulle trace d'une soumission des Castillans. La victoire associe à égalité Léonais et Castillans.

61. Sur le récit de cette genèse et celle, concomitante, d'un territoire castillan, voir G. M AR TIN, « Rodrigue de Tolède et l'invention d'un territoire castillan dans I'historiographie royale espagnole » in : R eprésentations de l'espace et du temps... (réf. note 13).

62. Les textes sont désormais trop longs pour être reproduits in extenso. $0 \mathrm{n}$ trouvera les textes originaux et leur traduction française dans M ART IN, Les J uges de Castille... , p. 339-352, 404405 n. 142 et 405-408 n. 144. Analyse: ibid., p. 317-430. 
mauvais penchants, suggère une concentration bonne et nécessaire du pouvoir dans la royauté.

Par rapport à ce tronc commun, les trois versions de l'E stoire d'E spagne se distinguent pourtant nettement l'une de l'autre.

La version "concise ${ }^{63}$, composée à l'apogée du règne d'Alphonse $X$, lorsqu'est achevée l'œurre juridique et que la quête de l'empire semble soudain toucher au but ${ }^{64}$, penche en faveur de la construction régalienne de Luc. La soumission des Castillans à la suite de la bataille d'O sma, " conforme au droit reconnu », est rétablie et conséquemment l'instauration de la magistrature castillane est sans effet décisif sur la configuration de l'espace politique en Espagne ${ }^{65}$. O n voit en outre les auteurs, peut-être en juristes qu'ils sont, introduire telle nuance qui a pour objet de rétablir les prérogatives du roi. À propos de $\mathrm{G}$ onzague N uñez, fils de N uño R asura, Luc avait écrit que les nobles castillans, après l'avoir « fait » juge, l'avaient « appelé » comte («G undisalvum N unnii sibi judicem fecerunt $\&$ etiam $C$ omitem vocaverunt »). Plus loin, son récit prêtait sans réserve à Ferrand $\mathrm{G}$ onzalez, dans la lignée de la tradition historiographique, le titre de comte ${ }^{66}$. Rodrigue noyait dans un premier temps le poisson, indiquant qu'à la mort de $\mathrm{N}$ uño R asura G onzague « avait été substitué à son père » et qu'on lui avait accordé de surcroît le commandement de la chevalerie. En revanche, il écrivait de Ferrand G onzalez qu'il avait été érigé en comte par les C astillans, dans I'enthousiasme partagé des nobles et du peuple: « tam a magnatibus et militibus, quam ab universis populis C astellanis in Comitem crearetur ». L es auteurs de la version « concise » de l'E stoire suivent Luc d'assez près dans le cas de $G$ onzague N uñez (« ils le firent seigneur de C astille et l'appelèrent comte $»)^{67}$. M ais, concernant Ferrand $G$ onzalez, ils rétablissent le droit royal en s'écartant communément de Luc et de R odrigue: c'est ici R amire II de León qui « fait » comte Ferrand G onzalez, et c'est seulement après cette investiture que Ferrand Gonzalez est déclaré « seigneur » des Castillans ${ }^{68}$. Sous ce rapport, la version concise de l'E stoire d'E spagne va plus loin que Luc dans l'affirmation des droits régaliens.

63. La version « concise » de l'E stoired'E spagne reste inédite. M anuscrits: M ARTIN, Les J uges de Castille... , p. 403 n. 141.

64. Sur ce contexte, M ART IN, Les ) uges de Castille..., p. 317-324.

65. Real Biblioteca de El Escorial, ms. Y-II-11 (dit ms. Y), fol. 398vª: «E tornose el R ey don $R$ amiro para leon con grand honrra. $E$ el conde ferrant gonçal uez finco ensu tierra con grand bien andança. $E$ dize don lucas de thuy que se metieron los castellanos estonces so el sennorio de $R$ ey ca entendieron que era dere cho connosçudo. pero defendieron ellos al gunas cosas senyaladas que les otorgo el R ey por ple tesias que pusie ron con $\mathrm{el} \gg$. Désormais ms. Y.

66. Luc n'évoque cependant le personnage que sous la désignation de « comte burgalais ». Jamais il ne lui prête le titre de « comte de Castille»...

67. M s. Y , fol. $396 r^{\circ}$ : « et fizieronlo sennyor de C astiella. et llamaronle cuende ».

68. M s. Y, fol. $397 \mathrm{r}^{\circ}$ : « et fizol cuende el R ey don R amiro. E t pues que el fue sennyor de castiella... » 
À Séville, au plus fort du cataclysme politique qui va emporter Alphonse, la version « critique ${ }^{69}$ de l'E stoire, raidie sur les principes les plus stricts du droit royal, confirme et même amplifie astucieusement cette préférence. Acceptant d'abord la leçon de Rodrigue pour mieux dénoncer les faits qu'elle rapporte (« tous les [riches] hommes et les chevaliers et les citoyens de $C$ astille se réunirent et érigèrent Ferrand $\mathrm{G}$ onzalez en comte $»)^{70}$, elle rétablit ensuite le récit que faisait Luc de la bataille d'O sma en augmentant, du reste, le bénéfice que pouvait en tirer la royauté. $N$ on seulement les auteurs marquent la magnanimité dont fait preuve le roi de León en oubliant pour l'occasion l'atteinte faite à ses prérogatives, mais ces dernières sont en outre immédiatement rétablies, et la faute effacée, dans l'investiture par R amire de Ferrand Gonzalez. La censure est plus forte que dans la version « concise » et le lecteur reçoit en prime une leçon de droit:

le comte Ferrand Gonzalez, qui était déjà seigneur en Castille, comme nous l'avons dit, dès qu'il sut [l'arrivée des Maures], envoya demander au roi $R$ amire de venir l'aider. Le roi R amire ne voulut pas alors se souvenir du mal qu'avaient fait les riches hommes de Castille en érigeant un comte sans sa permission - d'autant qu'ils ne pouvaient pas le faire d'eux-mêmes à bon droit, car nul n'a jamais pu faire un comte sinon le roi - et il réunit une grande armée et s'en fut aider le comte Ferrand Gonzalez

puis, la victoire acquise, « les $C$ astillans se mirent à la merci du roi pour le comte qu'ils avaient fait et le roi leur concéda le comte Ferrand Gonzalez »71.

Ainsi, I'historiographie alphonsine a donné le pas à L uc sur R odrigue quant à l'interprétation politique fondamentale de l'épisode. Pour autant que la chose ne soit pas immédiatement significative, il n'est pas sans intérêt de constater que, dans les valeurs défendues, Séville, où Luc avait placé un demi-siècle plus tôt ses espoirs anti-tolédans, se fit en effet I'héritière du message conçu à León. Et ceci d'autant plus que, cinq à six ans après qu'avait été composée la version « critique » de l'E stoire, sa

69. Seul le manuscrit $X-I-6$ de la Real Biblioteca de Escorial a été (récemment) édité: $M$ anuel ALVAR et al., Crónica de veinte reyes, Burgos: Excelentísimo Ayuntamiento, 1991. Pour la fin du récit de la bataille d'O sma (p. 83b-84a), la copie trahit l'œuvre. Ce passage est donc cité ici par le ms. 1501 de la Biblioteca Nacional (M adrid), fol. 5.

70. M anuel ALVAR et al., Crónica de veinte reyes, p. 83a: « [... ] allegáronse todos los [ricos] omnes e los caualleros e los çibdadanos de C astilla e alçaron conde a Fernand Gonçales».

71. «[... ] el conde fernan gonçalez que era ya señor en castilla. asi como diximos luego que lo supo enbio dezir al $R$ ey don $R$ amiro que le fuese a ayudar. $E$ I rey $D$ on rramiro no quiso entonçes menbrarse deel mal que fezieran. los rricos onbres D e castilla en alçar conde sin su mandado e demas que lo no pudien ellos fazer con derecho por sise mesmos ca ninguno pudo fazer conde si el rrey no lo faze e saco su hueste muy grande et fuese a ayudar al conde fernan gonçalez. [... ] los castellanos metieron se entonces a la mesura del rrey por el conde quefizieron eel rrey otorgoles el condefernan gonçales », Biblioteca Nacional, ms. 1501, fol. $5 \mathrm{r}^{\circ} \mathrm{b}-5 \mathrm{v}^{\circ} \mathrm{a}$. 
version « amplifiée $»^{72}$, conçue à Tolède, se montre quant à elle favorable aux thèses de Rodrigue Jimenez de R ada. Ici, Ferrand Gonzalez est fait comte par l'aristocratie castillane (« los ricos omnes et los otros caualleros ») sans intervention du roi de L eón ${ }^{73}$ et si la victoire d'O sma est obtenue avec le concours de celui-ci elle ne donne cependant lieu ni à la soumission des Castillans ni à la confirmation par R amire de Ferrand $\mathrm{G}$ onzalez dans sa charge comtale $\mathrm{e}^{74}$. Q uant au système de qualification sociale des acteurs, il complique considérablement le legs de Luc et de Rodrigue aux fins d'isoler la turbulence marginale des « hauts hommes » et de faire valoir l'appui que reçut de la noblesse unie, moralisée et civique des « omnes buenos » le pouvoir judiciaire puis comtal d'où émanera la royauté castillane ${ }^{75}$. D ans la cathédrale de Tolède, le molinisme, parfaitement lucide, après le traumatisme de la déposition d'Alphonse X par Sanche IV, quant à la nécessité d'amadouer et de gagner à soi la noblesse, retrouvait - débarrasée des penchants féodaux de l'ancien archevêque - la vision politique de Rodrigue. Et Tolède s'opposait désormais à Séville comme il s'était opposé naguère à L eón.

Georges M ART IN

ENS L ettres et sciences humaines

SEMH

GDR 2378 - SIREM

\section{Annexes}

1. « Post haec quidam maligni detractores coeperunt Ludovici Regis Francorum auribus instillare, quod Elisabeth uxorem ejus Imperator A defonsus genuerat de vilissima concubina. U nde ipse Rex turbatus, simulans se causa orationis ad sanctum Jacobum venire, venit in $\mathrm{H}$ ispaniam cupiens experiri, utrum verum esset, quod sibi maligni dixerant detractores. Addiderant enim quod ipse I mperator A defonsus erat vilis persona, $\&$ nullius momenti inter suos. Denegaverat etiam ei conjux ejus Elisabet thorum conjugalem, eo quod ita Rex Ludovicus imprope-

72. Édition: R. MENÉNDEZ PIDAL, op. cit. note 28. Légende des Juges de Castille: p. 387a-391b.

73. Ibid., p. 390a: « [... ] ouieron so conseio los ricos omnes et los otros caualleros de C astiella de alçar por conde a Fernan Gonçalez [... ] E t pues que el fue sennor de Castiella... »

74. I bid., p. 390a: «E t tornose el rey don R amiro pora $L$ eon con grand onrra, et el conde $F$ ernand $G$ onçalez finco en su tierra con grand bienandança ».

75. Sur cette lexicalisation nouvelle et l'exploitation sémantique de la lexie « omne bueno », M ART IN, Les J uges de Castille... , p. 362-383. 
rabat sibi. I mperator autem A defonsus ut audivit adventum generi sui Regis Ludovici, praecepit Regi Navarrae, \& comiti Barchinonae, ut omnem gloriam $\mathrm{H}$ ispaniae exhiberent ei. Sed ubi Rex Ludovicus venit L egionem, occurrit ei Imperator A defonsus cum tam glorioso apparatu, quod ipse Rex Ludovicus, \& Franci, quicum eo venerant, obstupuerint. Venit I mperator cum eo usque ad Sanctum Jacobum, $\&$ direxit nuncios per totum imperium suum ad omnes nobiles $\mathrm{C}$ hristianos, \& barbaros, quatenus Toletum ad ejus civitatem \& curiam convenirent; sed cum reversi à Sancto Jacobo Imperator \& R ex L udovicus, venirent Toletum, atque omnes Reges barbarorum, \& Christianorum Principes occurrerent I mperatori manus ejus osculantes, ultra quam credi potest $L$ udovicus admirans, dixit Imperatori : Per Deum, inquit, juro, quod non est gloria similis huic in toto mundo. Siquidem tantus erat apparatus holosericarum cortinarum, \& tentoriorum per agros extra urbem Toletanam, $\&$ diversorum insignium copia, quod à nullo poterant aestimari. Tantus erat nobilium virorum conventus, quod à nullo poterat dinumerari. Tanta offerebantur dona auri, argenti, lapidum pretiosorum, sericarum vestium, \& equorum Regi Ludovico \& suis, quod prae multitudine illis taedium generabant. I mperator autem conversus ad Regem Ludovicum, dixit ei : C erte Rex Francorum vides, \& ipse potes veritati testimonium perhibere, quod mentiti fuerunt, qui mihi \& filiae meae coram te in Francia detraxerunt. Filia mea est quam genui ex imperatrice Berengaria, quae filia fuit huius praesentis Barchinonensis comitis $R$ aymundi. Praesens erat cum multo gloriae apparatu comes $R$ aymundus, \& dixit Ludovico R egi : H abeas in magno honore \& reverentia Elisabeth neptem meam, alioquin cum auxilio praesentis domini mei Imperatoris Adefonsi promitto me tibi Parisiis in parvo ponte campale inferre bellum. Rex Ludovicus dixit eis: Gratia ago Deo, \& omnibus Sanctis eius, qui de nobilissimo sanguine vestro filiam vestram mihi dignatus est dare uxorem, quam semper dum vixero modis omnibus honorabo. Multa donaria oblata fuerunt tunc nobilissimo Ludovico Regi Francorum, sed nihil inde accipere voluit, nisi quendam smaragdum magnum, lapidem pretiosum cogente I mperatore A defonso, quem Rex Zafadola detulerat. R eversus est itaque R ex L udouicus in Franciam cum honore \& laetitia magna, \& hunc pretiosum lapidem, quem detulerat ab $\mathrm{H}$ ispania, monasterio beati Dionysii contulit; uxorem quoque suam Elisabeth tenerrime dilexit, \& modis quibuscumque potuit honoravit. $\mathrm{H}$ aec post obitum suum in Ecclesia beati Dionysii est sepulta, \& merito sancta Regina vocata; quia dum vixit in simplicitate spiritus \& afflictione carnis, studuit Domino deservire. Imperator autem Adefonsus cum in tanta consisteret gloria, \& corporis aegritudine laboraret, foedifragus populus barbarorum se contra illum erexit. Sed Imperator 
ut erat magnanimus dissimulans aegritudinem cum manu Gotthorum maxima contra $\mathrm{M}$ auros perrexit. Q ui ut viderunt cum magno exercitu, colla ei illico submiserunt. Sed crescente aegritudine dum ad propria rediret juxta portum, qui vocatur $\mathrm{M}$ uradal, in loco qui dicitur Fresneda, Domino, ut credimus, spiritum tradidit anno quadregesimo nono, ex quo regnare coepit; sepultus est in urbe regia Toletana. Priusquam vero moreretur, divisit imperium suum duobus filiis suis, Sancio scilicet \& Fernando. Sancio quidem dedit bellatricem Castellam, \& Fernando fidelem Legionem \& G allaeciam », Chronicon, p. 104-105.

2. «D eadventu R egis F ranciae in H ispaniam [LIB , VII.] CAP. IX. Post haec quidam maligni inter eum et $R$ egem Franciae volentes odium seminare, R egi Franciae obrepserunt, dicentes Elisabeth uxorem suam esse ortam ex vilissima concubina; et Rex Ludovicus volens experiri suggesta, iter arripuit ad Sanctum I acobum veniendi. Q uod praesentiens I mperator, Burgis occurrit turba herilium procerum comitatus, equorum et thesaurorum copiis adornatus, et gener eius ab eo et Rege Navarrae qui cum eo venerat, gloriosissime est susceptus, ita quod ipse Rex Franciae in aspectu tantae gloriae obstupebat. Cumque eum usque ad Sanctum I acobum produxisset, inde rediens, Toleti curiam celebravit, tam C hristianorum, quam A rabum eius imperio subiectorum, cui etiam interfuit $\mathrm{R}$ aimundus $\mathrm{C}$ omes Barcinonensis. Cumque R ex Franciae tam nobilem curiam inspexisset, admiratus omnia, dixit coram omnibus protestatus, similem curiam, similem apparatum in orbis ambitu nusquam esse, nec tantam supellectilem se vidisse. Tunc Imperator ostendens ei Comitem Barcinonae, qui in magno et honorabili apparatu erat: "Ecce, inquit, ex huius sorore Berengaria suscepi filiam quam vobis contuli in uxorem, et si vobis hanc ignobilem, et me inglorium suggesserunt, oculi vestri videant veritatem." Tunc Rex Ludovicus gratias egit, dicens: "Benedictus Deus, quod filiam tanti domini ex sorore tanti Principis habere merui in uxorem." O btulit autem Imperator infinita donaria, quae sui valore numerum excedebant; sed nil eorum voluit recipere Ludovicus, nisi quemdam carbunclum, quem in corona spinae Dominicae apud Sanctum Dionysium collocavit, quem etiam memini me vidisse », De rebus, p. 154-155.

3. «CHAPITRE XVe. Comment le roi de Fance vint en Espagne. En la quarante-septième année de règne de l'empereur Alphonse, qui fut en l'ère de mille cent quatre-vingt-treize années, quand l'année de l'Incarnation était de mille cent et cinquante-cinq, il advint que d'aucuns qui eurent goût de mettre désaccord entre l'empereur et le roi de France dirent à ce roi de France que sa femme I sabelle, la reine, l'empereur 
I'avait eue d'une concubine très vile. Le roi Louis, pour éprouver s'il en était ainsi, vint en Espagne sous couvert d'aller en pélerinage à SaintJacques. L'empereur, quand il le sut, s'en fut vers Burgos pour l'accueillir à grand honneur et avec grande compagnie de riches hommes et de nobles chevaliers, et bien appareillé, et le roi de Navarre était là avec lui. Et le roi de France fut si noblement accueilli qu'il s'en émerveilla beaucoup, et l'empereur l'emmena jusqu'à Saint-Jacques. De là, ils s'en retournèrent vers Tolède, et l'empereur tint là une très grande cour de chrétiens et de $M$ aures, et le comte R aymond de Barcelone y fut présent. Et à Tolède la cour fut si grande que toute la campagne hors de la ville était couverte de tentes et de toiles de soie et d'enseignes et de pennons de maintes manières. Et il y eut là si grand rassemblement de chevaliers et de nobles hommes qu'on n'en sut faire le compte, de sorte que le roi de France dit qu'il croyait bien que dans le monde entier il n'y avait si noble cour ni si bien appareillée ni si accomplie que l'était cellelà. Et furent donnés là au roi de France et aux siens tant de dons d'or et d'argent et de pierres précieuses et de draps de soie et de chevaux qu'ils en étaient ennuyés. Le roi de France ne voulut prendre autre chose qu'une [escarboucle] qu'il emmena à Saint-D enis, et qu'il plaça dans la couronne des épines de notre Seigneur Jésus-Christ. L'empereur dit alors au roi Louis de France: " Vous voyez par vous-même et pouvez entendre que vous ont menti ceux qui ont mis désaccord entre vous et ma fille, celle que j'ai eue de l'impératrice Bérengère qui fut fille du comte $\mathrm{R}$ aymond de Barcelone que voici. »C ar le comte était là devant, avec grande compagnie et très bien appareillée. Et le comte dit alors au roi L ouis: " Je vous dis, roi, d'honorer I sabelle, ma petite-fille, comme il est juste, sinon, sachez qu'avec l'aide de mon seigneur que voilà, l'empereur, je promets de vous livrer bataille rangée à Paris, au Petit-Pont. » Alors dit le roi Louis: « Dieu soit donc loué, qui voulut me donner pour femme fille de si haut seigneur et de sang si haut, et petite-fille de si grand chef commel'est le comte de Barcelone, et je m'en tiens pour très comblé, et, tant que je vivrai, je I'honorerai autant que je le pourrai comme l'on doit honorer dame de si haute guise. » Puis le roi s'en retourna vers sa terre à grand honneur et à grande joie, et dès lors il aima sa femme et l'honora en toutes les guises qu'il sut et put. Et quand elle mourut, elle fut enterrée dans le monastère de Saint-D enis, et elle est maintenant tenue pour sainte, car aussi longtemps qu'elle vécut elle aima beaucoup Dieu et lui fit grand service et mena vie très bonne et sainte. A cet empereur Alphonse, Dieu fit tant de grâce et donna tant de bonheur que tous les rois et tous les puissants d'E spagne furent sous ses ordres, aussi bien maures que chrétiens. C ar le roi Garsias de Navarre, et le comte $\mathrm{R}$ aymond de Barcelone, qui tenait alors le royaume d'Ara- 
gon en pouvoir, et les rois maures A ImohadisZ Zafadola, et le roi L ope, en même temps et tous ensemble furent tous ses vassaux. Et bien qu'il fût si haut et si puissant, jamais il ne voulut opprimer ni forcer aucun de ses vassaux. Au contraire, il en enrichit de nombreux avec son propre bien », ALVAR, Crónica de veinte reyes, p. 264-265.

4. «978. D u prétexte de la venue du roi de F rance en E spagne. Alors que l'empereur connaissait tant de bonheurs contre les M aures et parmi ses chrétiens, avec deux fils rois devenus grands et très vaillants chevaliers qui le gardaient chaque jour quotidiennement, certains hommes mauvais et félons et de mauvais lieu, comme le dit l'archevêque, voulant mettre mal, discorde et désamour entre l'empereur Alphonse et L ouis roi de France, médisaient à l'oreille de ce roi Louis, lui disant que sa femme la reine É lisabeth, l'empereur A Iphonse ne l'avait pas eue de sa femme la reine, mais qu'il l'avait faite en une concubine, du reste non noble mais femme vile. Ces hommes mauvais et vils lui ayant tenu maintes fois ces propos, il en pesa au roi L ouis et il les retourna dans sa tête, et il songea à éprouver la chose et à comment il pourrait le faire. Et il se mit alors en guise de roi pèlerin pour venir et éprouver s'il en était ainsi. Et il s'apprêta en cette guise et s'en vint en Espagne comme pèlerin, prétendant aller en pèlerinage à Saint-Jacques et suivre le chemin que prennent les autres pèlerins pour aller en pèlerinage vers cet apôtre. L'empereur sut à l'avance cette venue du roi L ouis de France et il convoqua tous ses riches hommes et sa très grande chevalerie et il leur dit comment venait le roi de France et qu'il allait en pélerinage à SaintJacques et qu'ils s'appareillassent tous très bien pour aller l'accueillir avec lui, car ils avaient tous grande obligation de le faire. Et eux s'appareillèrent tous très bien de plusieurs paires de draps très nobles, et de très bons chevaux et bien de saison, et de très bonnes mules. Et, comme le disent l'archevêque et les autres histoires qui s'accordent avec lui, le roi de $\mathrm{N}$ avarre était alors avec lui. Et tous se rassemblèrent à Burgos et ils partirent tous très bien appareillés à grand-merveille, chacun avec ses mules, très bonnes et très nombreuses et chargées de nombreuses et bonnes provisions, chacun les siennes, et ils partirent de cette façon accueillir L ouis roi de France. I ci, I'archevêque dit que, lorsque le roi de France vit l'accueil que lui faisait le roi de Castille et qu'il vit tant de bons hommes et si honorables, qui sur un bon cheval, qui sur une bonne mule, et qu'il vit encore si grande chevalerie de jeunes chevaliers, tous bien faits et grands et appareillés pour bien faire, et les autres apprêts si nombreux et si grands, l'archevêque dit que lorsque ce roi L ouis vit tout cela, qu'il s'en émerveilla tellement qu'il ne savait où regarder et qu'à cette vue seulement il resta ébahi. Et se joignirent au roi Louis l'empe- 
reur Alphonse, son beau-père, et Sanche, roi de Castille, son fils, et le roi Ferdinand de León, son frère, tous deux frères d'Élisabeth, reine de France, et beaux-frères du roi L ouis, ainsi que le roi de $N$ avarre qui était là avec eux, et le primat de Tolède et les autres prélats qui étaient là avec eux, et des comtes et des riches hommes et tout le reste de la chevalerie; et accompagnant tous en cette guise le roi de France, ils entrèrent tous dans Burgos. Et lorsqu'ils se furent logés et que le roi L ouis s'en fut voir l'impératrice Bérengère, sa belle-mère, s'il vit grandes merveilles avec l'empereur quand celui-ci vint l'accueillir avec force chevalerie et force prélats de sainte É glise, comme nous l'avons dit, s'il en vit plus, il n'en vit pas moins chez l'impératrice, si grande noblesse de dames se trouvait avec cette impératrice, les unes reines, d'autres infantes filles de rois, d'autres comtesses, d'autres riches femmes, d'autres infançones, et bien d'autres encore si nombreuses qu'il serait impossible de les compter et toutes si bien atournées que les servantes semblaient des dames. Et le roi L ouis comprit là très bien que les hommes félons qui lui avaient dit que la reine Élisabeth, sa femme, n'était pas fille de l'empereur et de l'impératrice Bérengère avaient menti et lui avaient dit fausseté, et qu'ils ne l'avaient fait que pour entrer en sa privauté et le flatter et obtenir quelque bien de lui. Et dès lors il tint pour bien meilleur et bien plus haut qu'il ne le faisait auparavant le fait d'É lisabeth, sa femme, et le roi Louis et toute la France la prisèrent et I'honorèrent et eurent plus grande vergogne envers elle désormais. Et le roi L ouis fut honoréà Burgos en cette guise: I'empereur le pourvut en abondance, lui et toutes les compagnies qui venaient avec lui, de toutes choses dont ils eurent besoin pour tout le temps qu'ils séjournèrent à Burgos. Et toutes les manières de préparation de mets que savaient faire les officiers et serviteurs qui venaient avec le roi L ouis, et toutes celles que connaissaient aussi les officiers et serviteurs de l'empereur, toutes étaient là préparées chaque jour en très grande abondance. Et lancer aux planches, et manier les armes, et combattre les taureaux, et jouer au jacquet et à d'autres jeux, et tous les divertissements et instruments qu'on put trouver en Espagne ou qui purent venir de France, la ville de Burgos en fut comblée en abondance pendant les jours que les rois y restèrent. Et enfin, lorsque le roi de France voulut continuer son pèlerinage et que l'empereur et ses fils y consentirent, se joignirent à lui l'empereur et ses fils les rois Sanche et Ferdinand et le roi de Navarre qui les accompagna tout du long et ils s'en furent avec lui, l'accompagnant et l'honorant tout au long de son chemin jusqu'à Saint-Jacques, l'empereur Alphonse les comblant de tout ce qui leur était nécessaire, tellement que rien ne leur fit défaut. Et à l'entrée de Saint-Jacques, et pendant son séjour, et au cours des veilles que le roi pèlerin devait faire, bien grandes furent les attentions et les 
merveilles et les honneurs qu'ils reçurent de la part du père et des fils et du roi Sanche [de Navarre] ${ }^{76}$ et du roi Ferdinand outre ceux dispensés par l'empereur. Car, bien que l'empereur ordonnât et défendît comme empereur et seigneur et qu'il fit ainsi toute sa vie, Sanche et Ferdinand eurent quelque pouvoir et ordonnèrent à la cour et sur les terres à partir du jour où l'empereur partagea pour eux le royaume, car nous disons que, pour les honneurs et les nobles faits, tous voulaient en faire et s'en acquitter, le père et les fils, car tous partageaient l'honneur et le pouvoir de seigneurie. Et une fois achevés les veilles et les prières et les honneurs rendus à Dieu, le roi Louis voulut se recommander à la grâce de l'empereur et des rois ses fils et du roi de Navarre et des autres chevaliers et du primat de Tolède et des autres prélats (qui, pour l'amour de l'empereur et de ses fils les rois et de leur honneur allaient là, s'acquittant auprès d'eux de leurs offices et tenant les maisons et les honorant en cela et en d'autres choses autant qu'ils pouvaient et savaient), et prendre congé de tous et reprendre la route depuis son pélerinage vers sa terre en France. $M$ ais alors, l'empereur et ses fils l'entreprirent d'aller avec eux à Tolède, et ils l'en prièrent tellement qu'il dut le faire. Et tousl'emmenèrent de là, et de même qu'ils l'avaient amené de Burgos à SaintJacques, ils l'amenèrent de Saint-Jacques à Tolède, ainsi que le roi de $N$ avarre qui était encore avec eux, en le[s] comblant toujours très abondamment de tout ce dont il était besoin. Et lorsqu'ils furent à Tolède, l'empereur réunit là une grande cour où se rendirent aussi bien des $M$ aures arabes qui étaient sous son empire que les chrétiens. Et $R$ aymond, comte de Barcelone, fut présent à cette cour. Et quand le roi L ouis de France regarda et vit si noble cour et toutes les choses s'y faire si noblement, s'émerveillant de tout, il dit en présence de tous devant cour, jurant et attestant, comme le raconte l'archevêque, qu'il n'y avait si noble cour ni tel appareil nulle part sur le cercle de la terre et qu'il n'avait jamais vu si grande noblesse de choses toutes si nombreuses et si nobles. Alors l'empereur tint que le moment était venu, et se déclara dans les propos que nous allons vous dire. II montra à Louis, roi de France, le comte de Barcelone qui était venu à cette cour en grand appareil et à grand honneur, et il dit ceci au roi Louis: «Roi Louis, voyez et sachez qu'en l'impératrice Bérengère, sœur du comte de Barcelone que voici, j'ai fait ma fille Élisabeth, celle que je vous ai donnée pour femme et avec qui vous êtes aujourd'hui marié ». Alors, le roi Louis, à ces mots, leva les mains au ciel, rendant grâces à Dieu pour cela, et dit: «Béni soit D ieu puisquej'ai mérité d'avoir pour femme légitime fille de si grand seigneur comme l'est Alphonse, empereur des Espagnes, et fille de sœur de si grand prince comme l'est le comte de Barcelone! » Et le roi Louis de France dit ces paroles devant cour à 
Tolède et il se tut. Alors, Alphonse, empereur des Espagnes, donna au roi L ouis de France tant de ses dons, mules et chevaux et pierres précieuses et perles et étoffes prisées, ouvrées de broderies à la manière de la terre des $M$ aures, que, au dire de l'archevêque, ils ne sauraient être comptés, et dont il dit encore que leur valeur excédait leur compte. $M$ ais il dit aussi que le roi Louis ne voulut prendre aucun de ces dons, sinon une escarboucle qui était de celles qui furent en la couronne d'épines que l'on posa sur la tête de Jésus-C hrist le jour de sa passion. Et le roi Louis prit seulement cette pierre parmi tous les dons de l'empereur Alphonse, et il emmena celle-ci et la mit sur l'autel et parmi les reliques de Saint-D enis de France. Et l'archevêque Rodrigue dit aussi qu'il se souvient d'avoir vu cette pierre parmi les reliques de ce monastère de Saint-D enis. Ceci fait et conclu, le roi de France prit congé pour partir et il répéta lors de son départ qu'il se tenait pour très honoré de son mariage avec Élisabeth, fille de l'empereur A lphonse et de l'impératrice Bérengère, et comblé par elle, et qu'aussi longtemps qu'il vivrait, il l'honorerait toujours autant qu'il le pourrait, comme dame de si haute guise doit l'être. Et enfin, au terme de tout cela, le roi L ouis prit congé de tous et retourna en France vers sa terre à grand honneur et très joyeux, et dès Iors il aima sa femme Élisabeth bien plus qu'il n'en avait coutume, et I'honora de toutes les façons qu'il sut et put aussi longtemps qu'ils vécurent tous deux. Et le temps venu, quand elle mourut, elle fut enterrée dans le monastère de Saint-D enis, qui est la plus honorable sépulture de France, et elle fut tenue pour sainte, car tant qu'elle vécut elle aima Dieu et fit très bonne vie. À l'empereur Alphonse Dieu fit tant de grâce et donna tant de bonheur que tous les rois et tous les puissants d'E spagne furent sous ses ordres, aussi bien maures que chrétiens. $C$ ar le roi $\mathrm{G}$ arsias de $\mathrm{N}$ avarre, et le comte $\mathrm{R}$ aymond de Barcelone, qui tenait alors le royaume d'A ragon en pouvoir, et les rois maures A benfadiz et Z afadola, et le roi $L$ ope, en même temps et tous ensemble, furent tous les vassaux de cet empereur Alphonse. Et bien qu'il fût si haut et si puissant, jamais il ne voulut opprimer ni forcer aucun de ses vassaux. Au contraire, il en enrichit de nombreux avec son propre bien. À présent nous laissons ce propos, le roi Louis étant parti pour sa France, et l'empereur Alphonse pour sa terre et son Espagne avec beaucoup de bonheur et de joie et d'honneur. Et parce que les gens n'ont jamais su rester tranquilles, sans que, d'une façon ou d'une autre, ils ne cherchent tel ou tel trouble, nous parlerons de certains $M$ aures qu'on appelait les Almohades: comment ils quittèrent I'Afrique et passèrent en Espagne, et ce qu'ils y firent et d'où ils eurent ce nom », M ENÉNDEZ PIDAL, Primera crónica general de E spaña, 2, p. 656-658. 